\title{
Maternal Serum Cytokine Concentrations in Healthy Pregnancy and Preeclampsia
}

\author{
Toni Spence $(\mathbb{D}$, Philip J. Allsopp $\mathbb{D}$, Alison J. Yeates $\mathbb{D}$, Maria S. Mulhern $\mathbb{D}$, J. J. Strain $\mathbb{D}$, \\ and Emeir M. McSorley
} Nutrition Innovation Centre for Food and Health (NICHE), School of Biomedical Sciences, Ulster University, Coleraine,
Northern Ireland, UK

Correspondence should be addressed to Emeir M. McSorley; emeirmcsorley@gmail.com

Received 21 November 2020; Revised 21 January 2021; Accepted 28 January 2021; Published 23 February 2021

Academic Editor: Tamas Zakar

Copyright (C) 2021 Toni Spence et al. This is an open access article distributed under the Creative Commons Attribution License, which permits unrestricted use, distribution, and reproduction in any medium, provided the original work is properly cited.

\begin{abstract}
The maternal immune response is essential for successful pregnancy, promoting immune tolerance to the fetus while maintaining innate and adaptive immunity. Uncontrolled, increased proinflammatory responses are a contributing factor to the pathogenesis of preeclampsia. The Th1/Th2 cytokine shift theory, characterised by bias production of Th2 anti-inflammatory cytokine midgestation, was frequently used to reflect the maternal immune response in pregnancy. This theory is simplistic as it is based on limited information and does not consider the role of other T cell subsets, Th17 and Tregs. A range of maternal peripheral cytokines have been measured in pregnancy cohorts, albeit the changes in individual cytokine concentrations across gestation is not well summarised. Using available data, this review was aimed at summarising changes in individual maternal serum cytokine concentrations throughout healthy pregnancy and evaluating their association with preeclampsia. We report that TNF$\alpha$ increases as pregnancy progresses, IL- 8 decreases in the second trimester, and IL- 4 concentrations remain consistent throughout gestation. Lower second trimester IL-10 concentrations may be an early predictor for developing preeclampsia. Proinflammatory cytokines (TNF- $\alpha$, IFN- $\gamma$, IL-2, IL-8, and IL-6) are significantly elevated in preeclampsia. More research is required to determine the usefulness of using cytokines, particularly IL-10, as early biomarkers of pregnancy health.
\end{abstract}

\section{Introduction}

The importance of the maternal immune system in the establishment and maintenance of successful pregnancy is well researched. The maternal immune system must support immune tolerance to the fetus while maintaining innate and adaptive responses to prevent pathogen invasion. There are key roles for immune cells during pregnancy, particularly uterine natural killer cells (uNK) at the implantation site [1] and at the maternal-fetal interface [2], mediating important processes involved in placentation, for example, angiogenesis. Research exploring the maternal-fetal interface dates back to 1953 when Medawar defined the fetus as an allograft [3] and the uterus was originally proposed to be an immune privileged site [4]. Further theories exist on how the maternal immune response adapts to pregnancy and enables survival of the fetus including the proposed anatomical barrier effect between the mother and fetus [5], maternal systemic and local immune suppression, a lack of major histocompatibility complex (MHC) antigens on fetal tissue, and the maternal Th1/Th2 cytokine shift [6]. Research has focused on the maternal cytokine profile and how it differs during pregnancy, suggesting that a balance between pro- and antiinflammatory responses is important for optimal pregnancy outcome [7].

Cytokines are signalling proteins directing biological processes throughout pregnancy, from implantation to parturition. The first trimester is a vulnerable stage of pregnancy as complications can be linked back to abnormal placental development [8]. While implantation and placental development are proinflammatory processes, the maternal immune response acts to control inflammation through regulatory and anti-inflammatory mediators [9]. The pregnancy "Th2like phenomenon" was first described by Wegmann and 


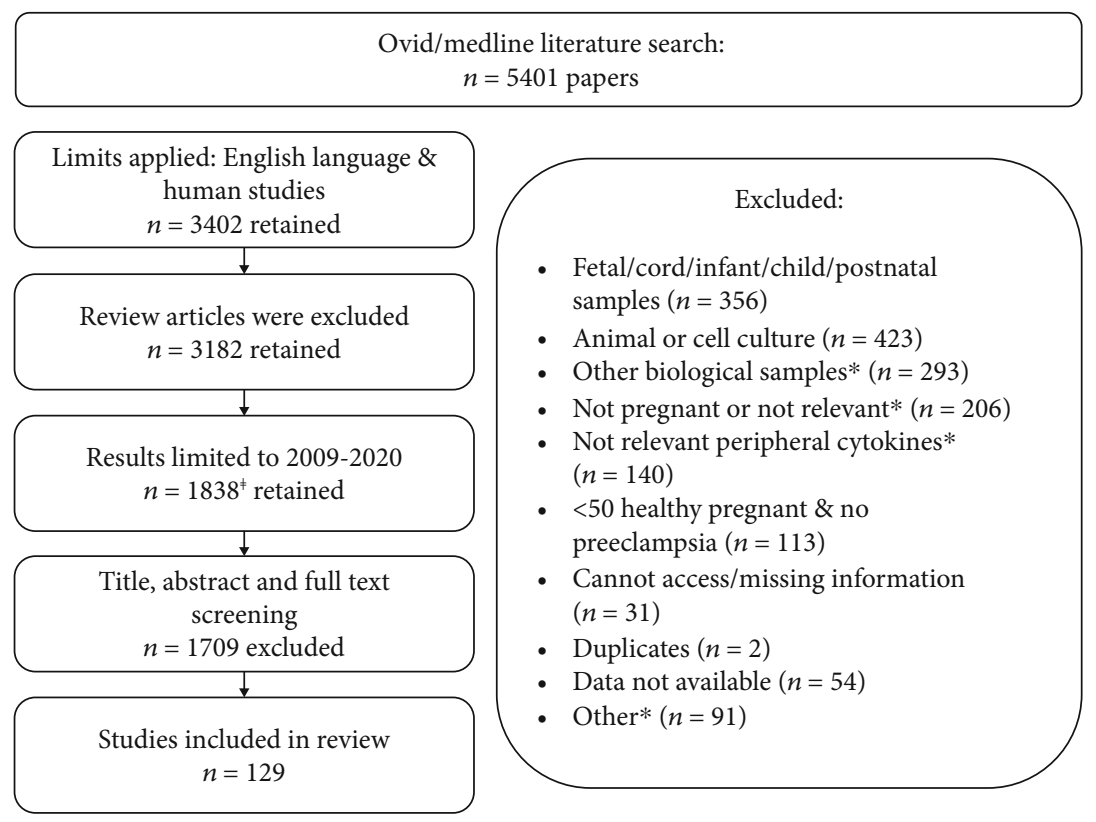

Figure 1: Summary of the literature search and papers retained or excluded. ${ }^{\circledR}$ Including four additional papers identified from references. ${ }^{*}$ Other biological samples: e.g., plasma, whole blood, CSF, and PBMCs; not pregnant or not relevant: e.g., IVF, recurrent miscarriage, fertile and infertile women, and infection or periodontitis/gingivitis; not relevant peripheral cytokines: e.g., gene polymorphisms or expression; other included not healthy pregnancy or preeclampsia and adolescent or twin pregnancy.

colleagues, proposing a bias towards Th2 cytokine production to achieve immune tolerance to the fetus [10]. Research using isolated peripheral blood mononuclear cells (PBMCs) from pregnant women between the first and third trimester suggested a "shift" towards Th2 cytokine production during healthy pregnancy compared to nonpregnant women [11]. Following extensive research, the proposed Th1/Th2 gestational cytokine shift was characterised by increased antiinflammatory Th2 cytokine production in the second trimester $[1,12]$. Furthermore, adverse pregnancy complications including preeclampsia have been associated with increased Th1 proinflammatory cytokines $[13,14]$. In recent years, however, the Th1/Th2 cytokine profile has been deemed too simplistic. Research now focuses on many contributing mediators of the immune response including regulatory $\mathrm{T}$ cells (Tregs) [15] and Th17 cells [16]. A recent review summarised how an imbalance between maternal proinflammatory cytokines and immune regulatory factors (Tregs and IL-10) is a key contributor to preeclampsia [17]. An indepth understanding of the changes in the maternal cytokine profile could distinguish successful pregnancy from pregnancy complications and help provide a greater understanding of the immune response during pregnancy.

Alterations in the normal immune response during pregnancy may contribute to the onset of pregnancy complications. Hypertensive conditions occur during approximately $10 \%$ of pregnancies in the UK with a wide variation in incidence worldwide [18]. In women with normal blood pressure prior to pregnancy, preeclampsia is characterised by hypertension and proteinuria or hypertension with end organ dysfunction with or without proteinuria $[19,20]$. The disorder, which develops at $\geq 20$ weeks, is associated with infant complications including fetal growth restriction [21]. Uncon- trolled, increased proinflammatory responses alongside less regulatory or anti-inflammatory cytokines are important contributing factors to the pathogenesis of preeclampsia [22], and the maternal cytokine profile has been shown to differ between normotensive pregnancy and preeclampsia [23-25]. Research has shown differences in cytokine concentrations in early pregnancy between healthy women and those who later developed preeclampsia, suggesting that cytokines may be early predictors of preeclampsia [26]. As a result, it is plausible that maternal cytokine concentrations may be potential predictors of adverse pregnancy complications.

Although the maternal immune response is well researched, the change, if any, in individual peripheral cytokines across gestation has not been well summarised. In the past, cytokines have been difficult to detect in maternal plasma [27] and serum [28] from healthy pregnancy, but advances in technology over time has improved the sensitivity of immunoassays used to measure cytokines. Using available data from the current literature, this review was aimed at summarising changes in individual maternal serum cytokine concentrations throughout healthy pregnancy and evaluating associations between maternal serum cytokines and preeclampsia.

\section{Methods}

The research strategy utilised Ovid/Medline databases. Initial literature searches were conducted between $8^{\text {th }}$ May and $7^{\text {th }}$ June 2019. The search was repeated on the $15^{\text {th }}$ April 2020. Figure 1 summarises the results of our literature search and the papers retained or excluded. Human studies published in the English language on or after 2009 were included if cytokines were measured in maternal serum from a cohort of $\geq 50$ healthy pregnant women or at $>1$ 
time point across the three trimesters, regardless of sample size. To obtain data on preeclampsia, the same inclusion criteria were applied with the exception that there was no restriction on sample size.

Exclusion criteria were cytokines measured in other biological samples (e.g., plasma, whole blood, or PBMCs), murine or in vitro models, where there was a different group of participants per sampling time point, and studies which did not report cytokine data (e.g., data were only presented in graphs). Four additional papers were included from the references of studies. Owing to the high volume of papers identified $(n=1838)$, we excluded studies consisting of $<50$ healthy pregnant women. For this review, cytokine concentrations were obtained from published work, converted to $\mathrm{pg} / \mathrm{mL}$ for standardisation where possible, expressed as median unless otherwise stated, and reported to 2 decimal places. The gestational age of sample collection is provided where possible based on the mean or median as stated in the original paper and rounded to the nearest whole number. The following cytokines are discussed in this review: IFN $-\gamma$, TNF- $\alpha$, IL-1 $\beta$, IL-2, IL-4, IL-6, IL-8, IL-10, IL-12, IL-13, IL17 , IL-18, IL-33, and TGF- $\beta$. The existing data for cytokine concentrations within healthy pregnancy are displayed in Tables 1 and 2 while data for women who developed preeclampsia are in Table 3.

\section{Cytokines in Healthy Pregnancy}

Interferon-gamma (IFN- $\gamma$ ) is a proinflammatory cytokine secreted as part of the immune response to damageassociated molecular patterns (DAMPs) or pathogenassociated molecular patterns (PAMPs), by immune cells including natural killer (NK) and Th1 cells [29]. The active protein interacts with a heterodimeric receptor comprising IFN- $\gamma \mathrm{R} 1$ and IFN $-\gamma \mathrm{R} 2$, resulting in the activation of the JAK-STAT signalling pathway to coordinate immune responses [30]. IFN- $\gamma$ is a key mediator in response to viral pathogens [31,32] and tumours [33]. At the maternal-fetal interface, IFN- $\gamma$ contributes to the establishment and maintenance of successful pregnancy, mediating endometrial vascular remodelling and angiogenesis [34]. One study observed significant increasing mean concentrations of IFN- $\gamma$ between the first, second, and third trimesters of healthy pregnancy (91.05 pg/mL, $124.50 \mathrm{pg} / \mathrm{mL}$, and $131.05 \mathrm{pg} / \mathrm{mL}$, respectively) [35], while others reported significantly lower IFN- $\gamma$ concentrations in the third trimester compared to the first $[36,37]$ and second [38] trimesters. Another study detected higher IFN- $\gamma$ concentrations in the third trimester compared to the second [39]. The study participants, however, were overweight and obese which may have influenced their results as obesity is associated with elevated cytokine concentrations including IFN- $\gamma$ [40]. High IFN- $\gamma$ concentrations may also reflect subclinical or asymptomatic infections. Owing to the antiviral activity of IFN- $\gamma$, controlling for infections is an important factor which restricts comparability of data. While some studies included in this review adjusted for the presence or absence of infection or took infection into consideration when including/excluding participants [38, $41]$, others did not specify this criterion [39, 42]. Meanwhile, a recent study showed no significant change in maternal serum IFN $-\gamma$ concentrations across 4 time points $(10,12$, 19, and 24 weeks) [43]. From the existing data discussed, there is no obvious trend or pattern to the changes in IFN$\gamma$ and any changes observed may reflect the role of IFN in inflammation owing to infection.

Tumour necrosis factor (TNF)- $\alpha$ is a proinflammatory cytokine which is encoded on chromosome 6 and acts through TNF receptors (TNFR1 and TNFR2) expressed by most cells of the immune system [44]. Apart from its key role in inflammatory responses against infection [45], TNF- $\alpha$ is an important regulator of normal cell function, influencing vital biological processes including cell proliferation [46], apoptosis [47], and the production of other cytokines such as IL-6 [48]. Apoptosis is a critical process to regulate placenta trophoblast cell survival in normal pregnancy [49]. TNF- $\alpha$ binding to TNFR1 can mediate cell death through interactions with the TRAAD adaptor protein and fasassociated death domain (FAAD) or survival through the binding of TRAAD, TNF receptor-associated factor (TRAF), and the receptor interaction protein [50]. In healthy pregnancy, maternal serum TNF- $\alpha$ concentrations are significantly higher in the second and third trimesters compared to the first [51]. Another study found that mean TNF- $\alpha$ concentrations significantly increased between the first, second, and third trimesters of healthy pregnancy $(108.00 \mathrm{pg} / \mathrm{mL}$, $153.01 \mathrm{pg} / \mathrm{mL}$, and $172.89 \mathrm{pg} / \mathrm{mL}$, respectively) [35]. Others have also observed significantly higher TNF- $\alpha$ concentrations in the third trimester compared to early pregnancy $[52,53]$. Significant increases in maternal serum TNF- $\alpha$ concentrations are also reported between the first and second $[54,55]$ and the second and third trimesters [56]. In contrast, others detected a significant reduction in maternal serum TNF- $\alpha$ concentrations between the first and third trimesters $[36,37]$. There is also evidence of no change in TNF- $\alpha$ between various time points across healthy pregnancy $[38,43,57-61]$. Overall, it is likely that TNF- $\alpha$ concentrations increase as gestation progresses albeit not excessively and may support the increased metabolic needs associated with pregnancy.

Interleukin-6 (IL-6) is a pleiotropic cytokine largely produced by monocytes and macrophages but also by other immune and nonimmune cells including $\mathrm{T}$ cells and endothelial cells. In the innate immune response, macrophages secrete IL-6 in response to PAMPs which are bound to pattern recognition receptors. When secreted, IL- 6 moves to the liver where it stimulates production of acute phase proteins such as C-reactive protein (CRP) [62], thereby promoting inflammation. IL-6 mediates embryo implantation and placental development [63]. Maternal serum IL-6 concentrations significantly increase during healthy pregnancy [64]. Others also reported significantly higher IL- 6 concentrations in the third trimester in comparison to samples collected earlier in pregnancy $[35,59,65,66]$. Repeated sampling in the first half of healthy pregnancy has shown that IL- 6 concentrations decrease between the first and second trimesters [43]. In contrast, data from another study suggests the opposite, reporting higher IL-6 concentrations in the second trimester compared to the first trimester [54]. Notably, while 


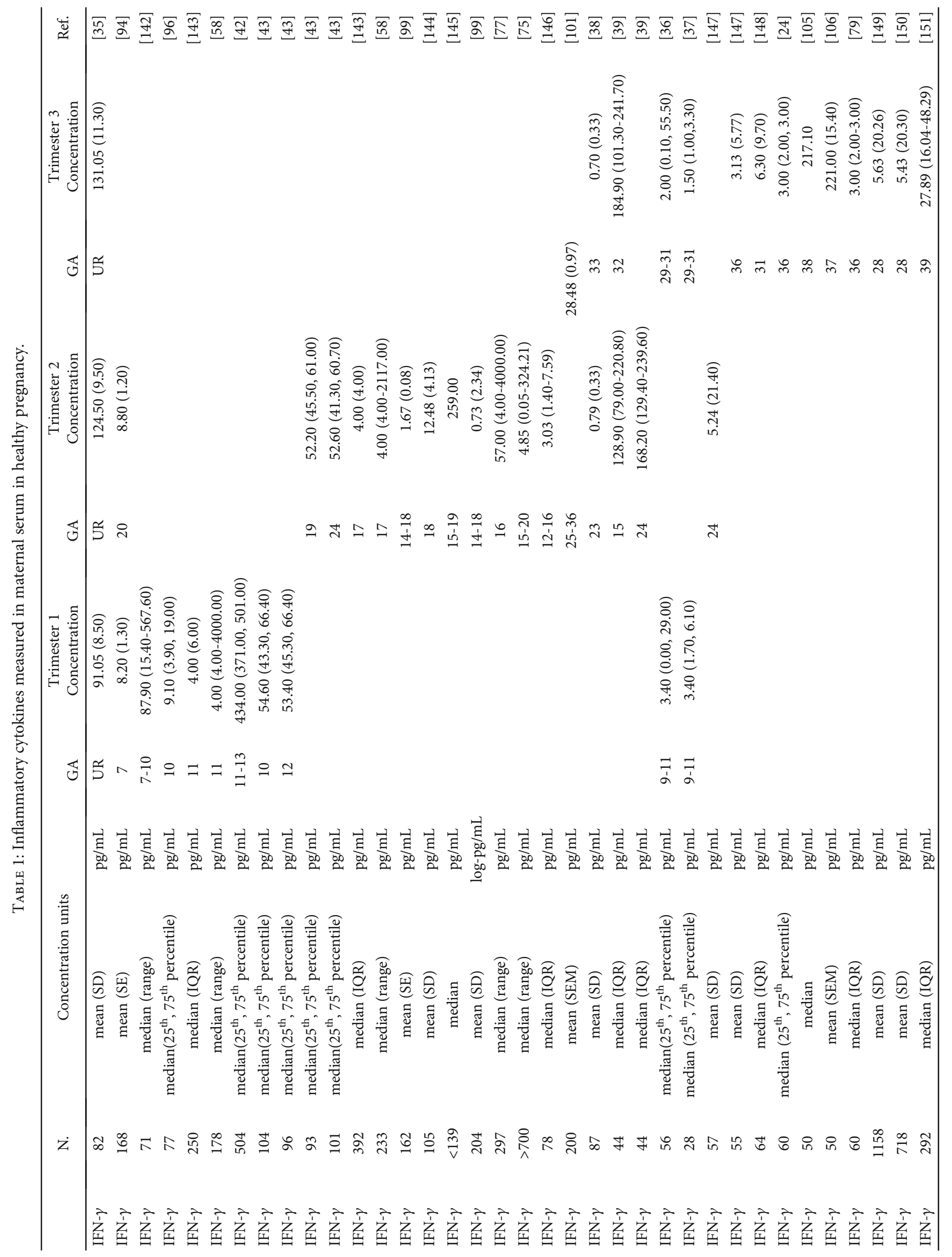




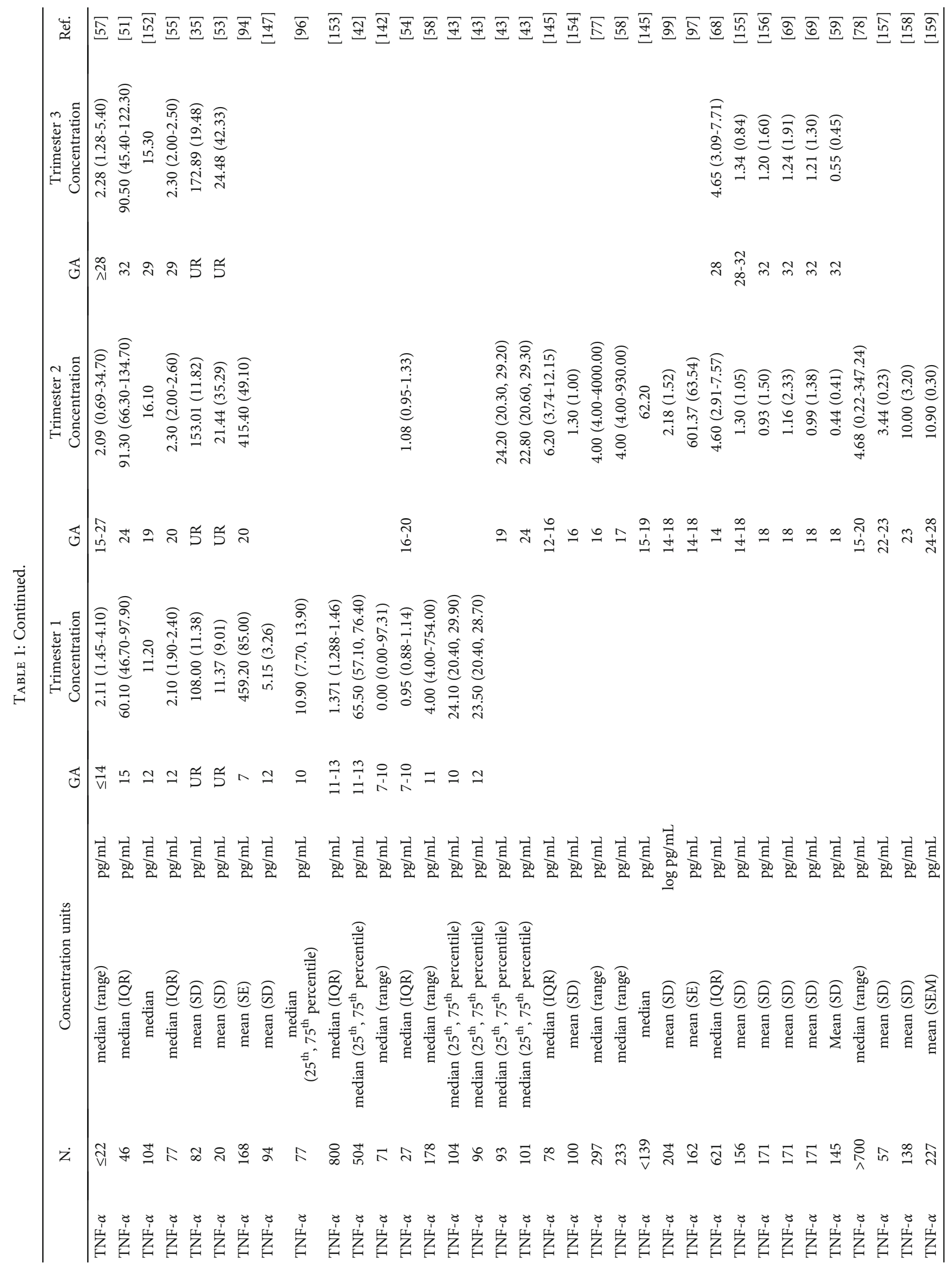




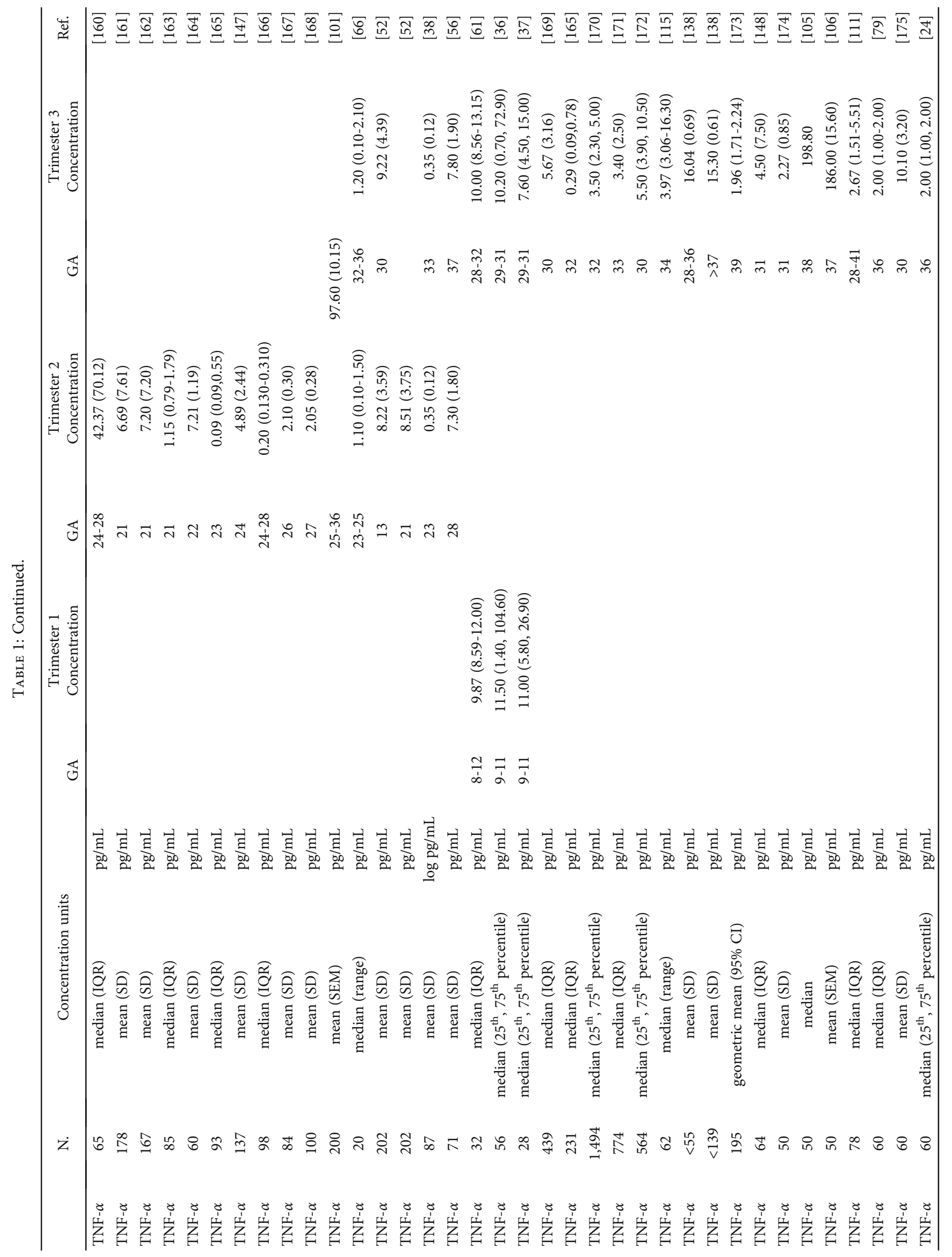




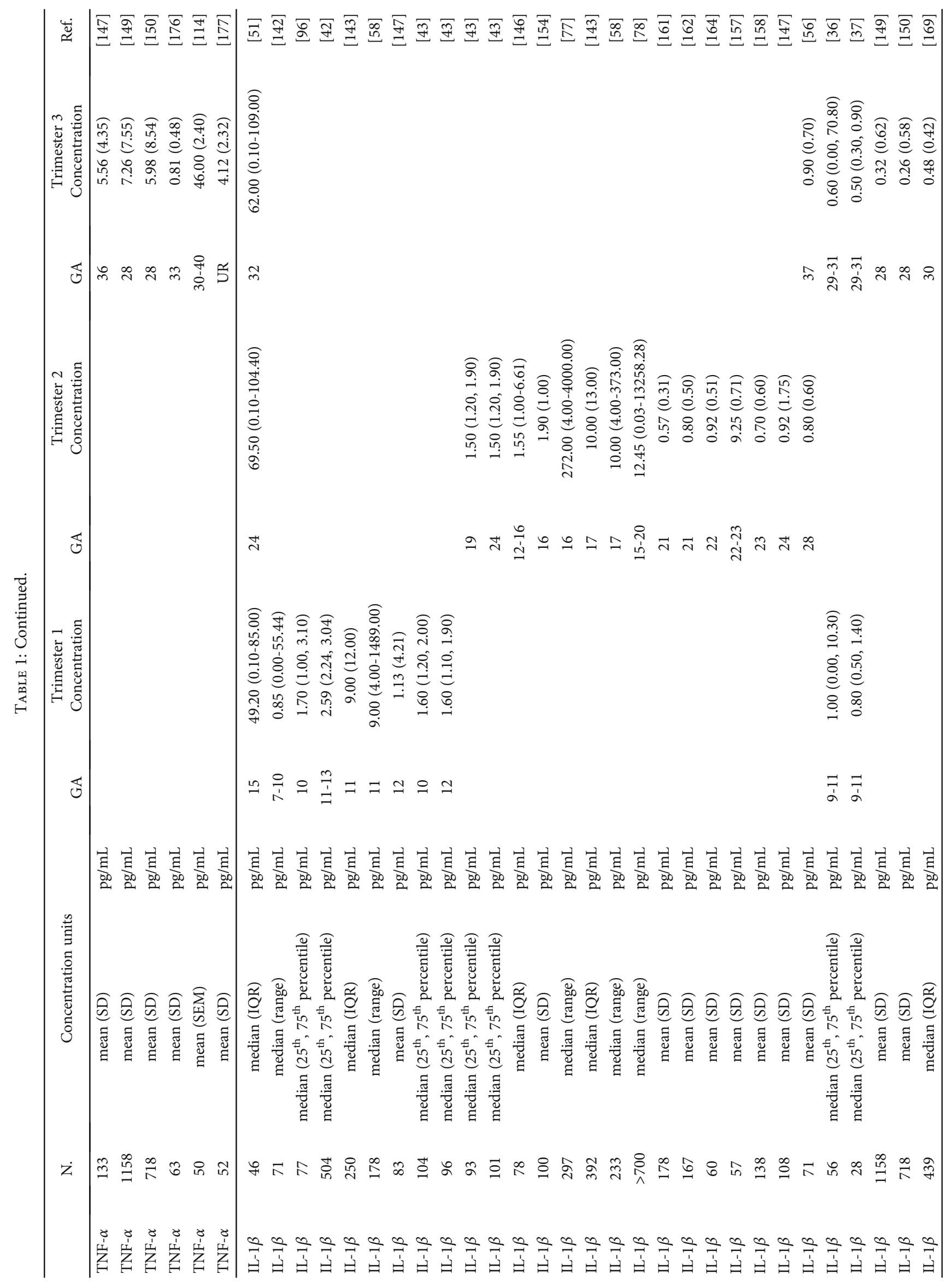




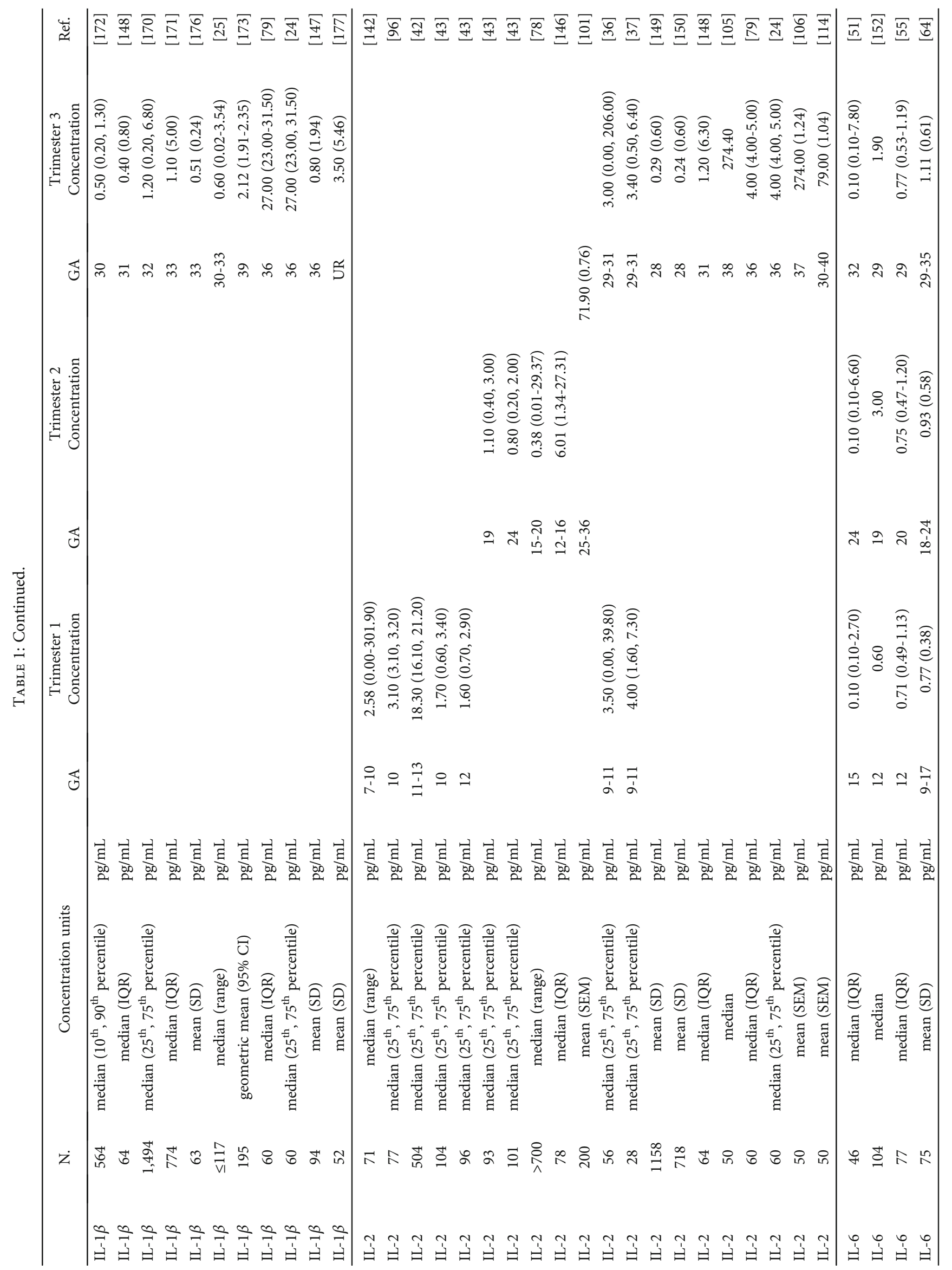




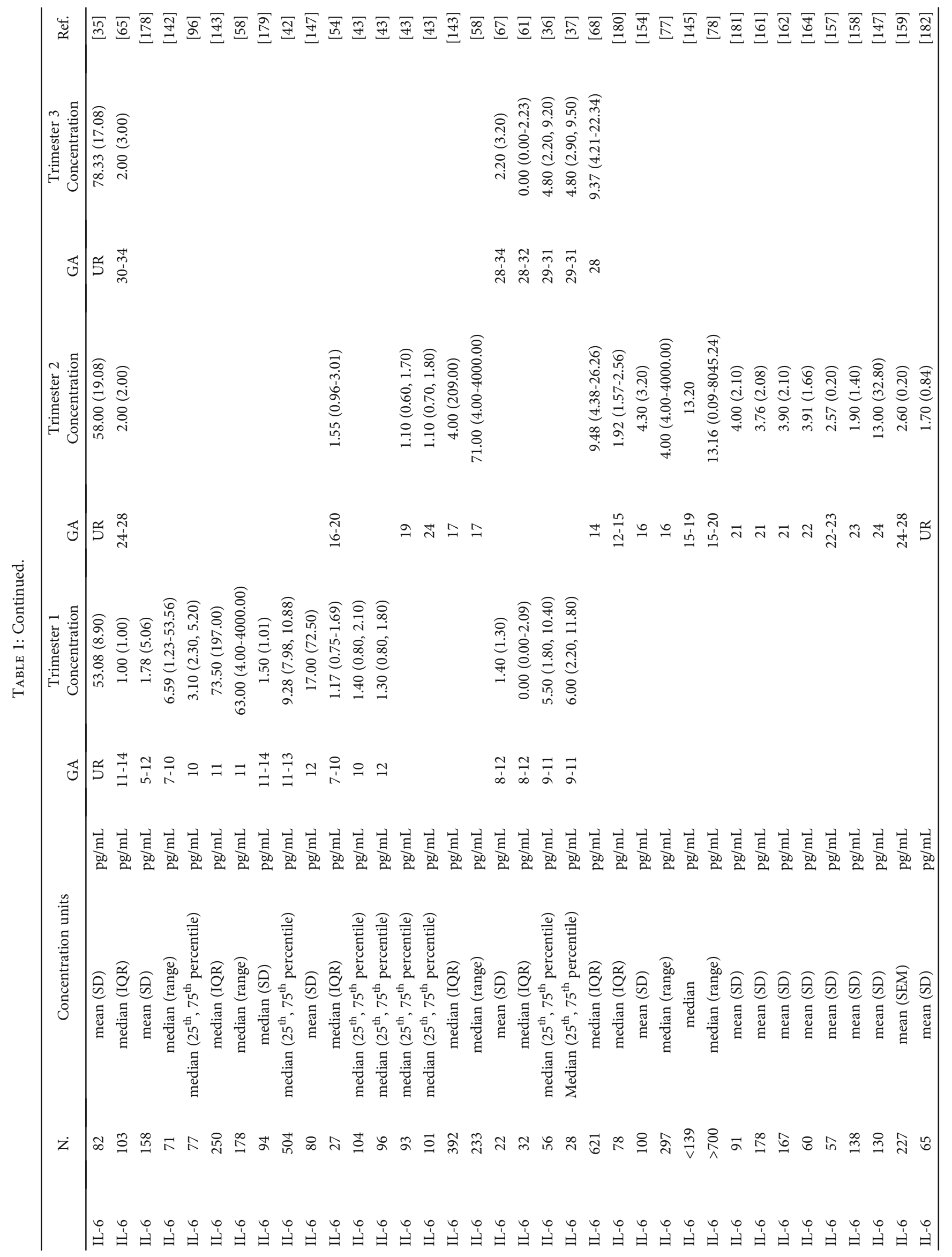




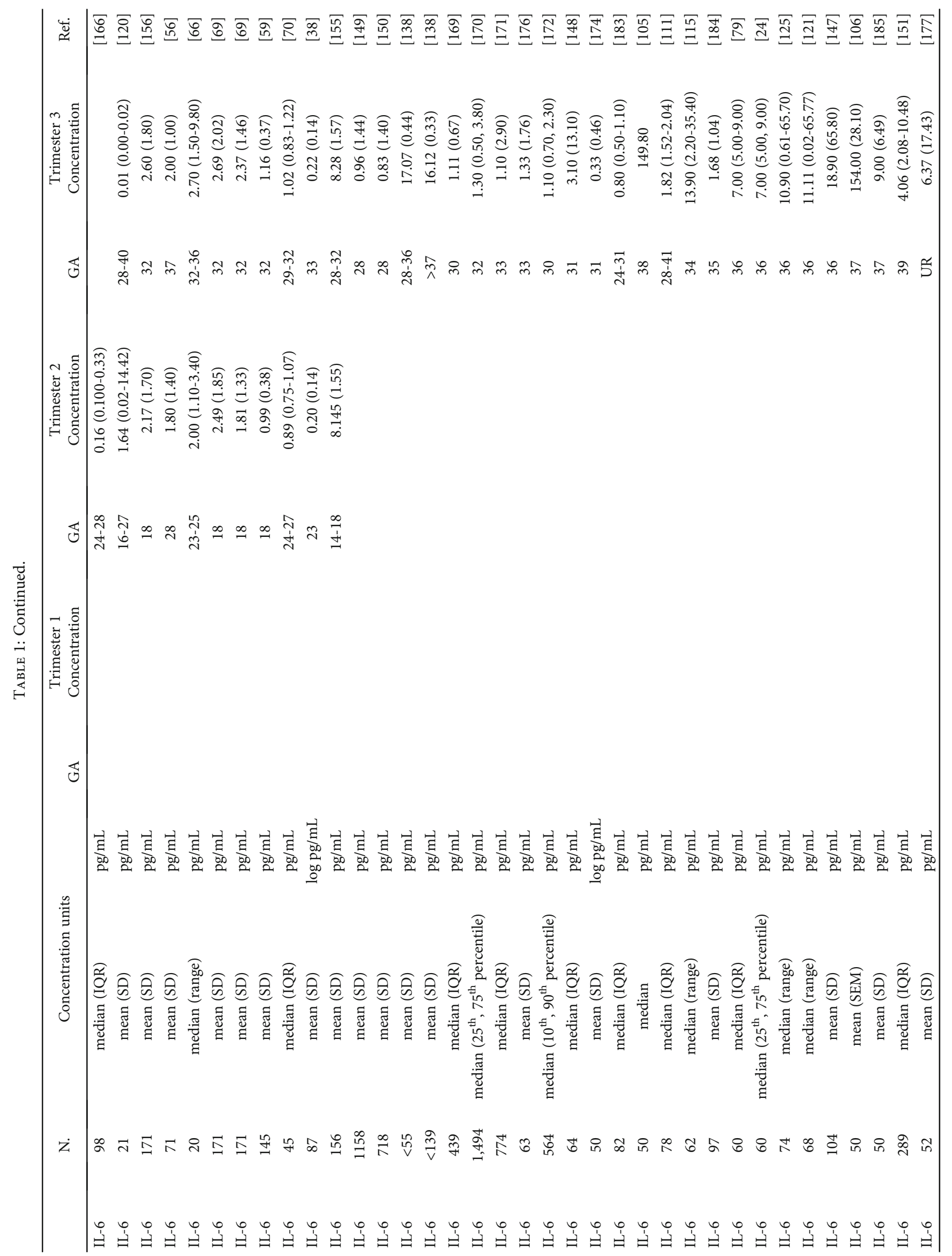




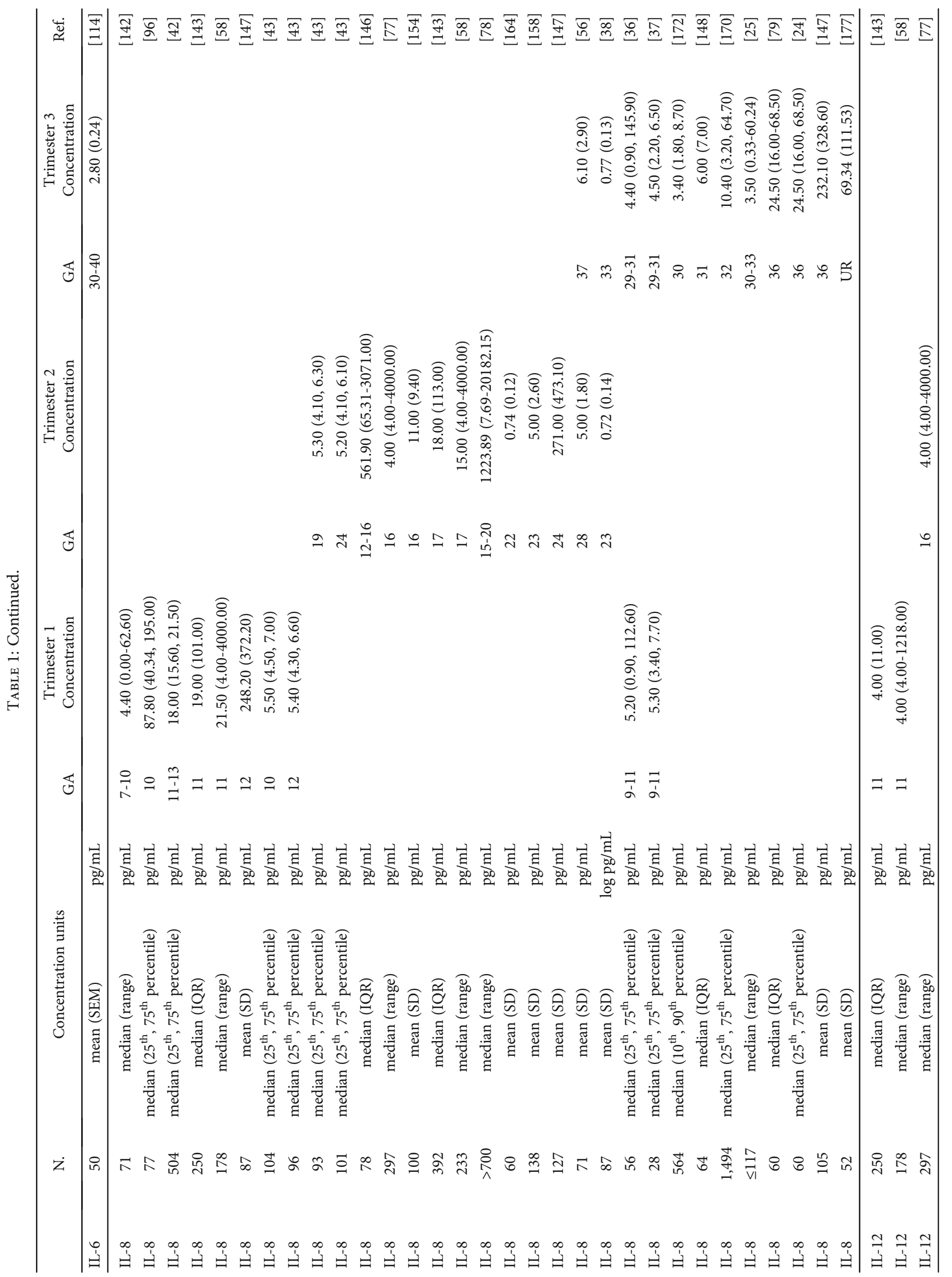




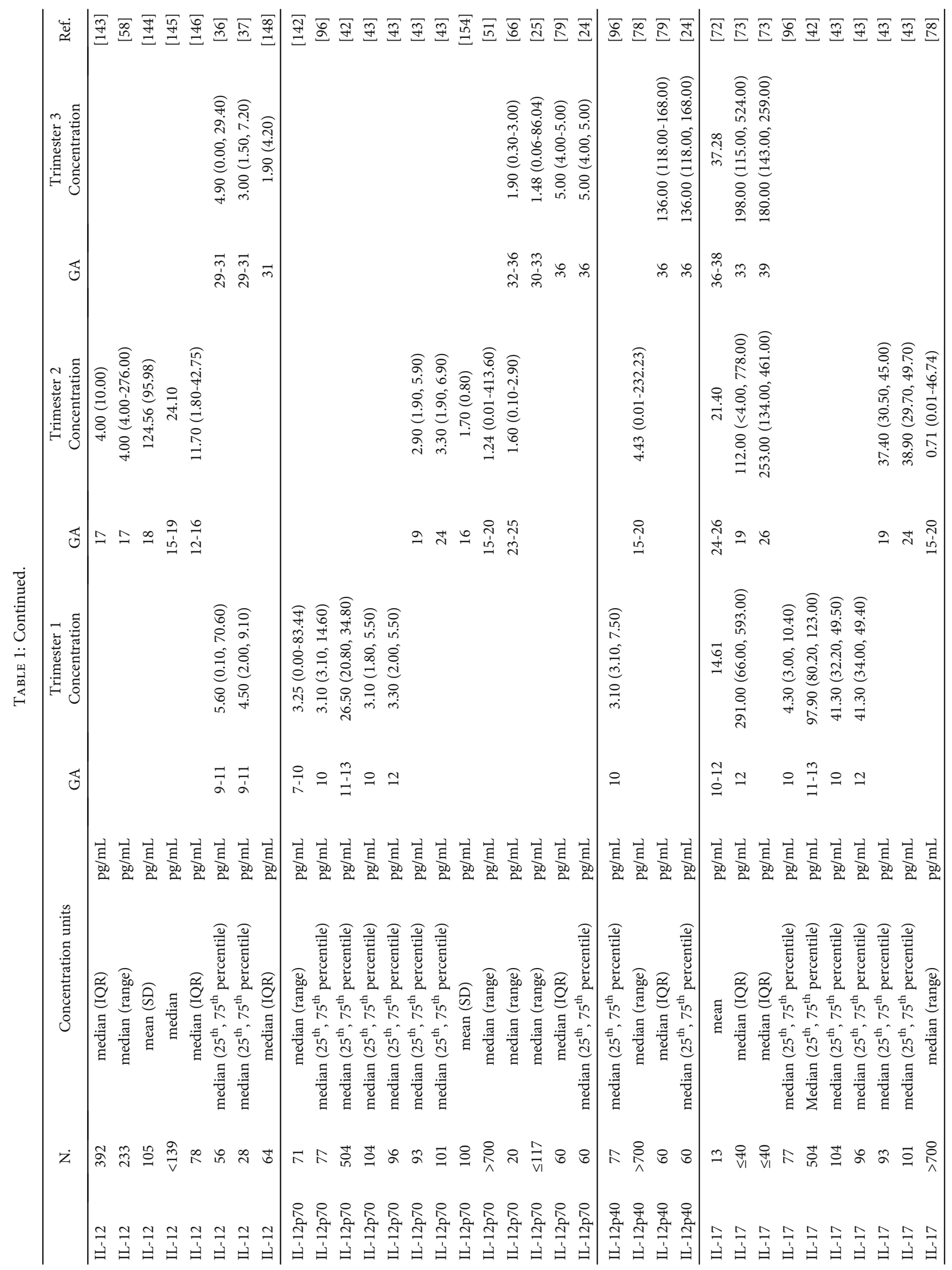




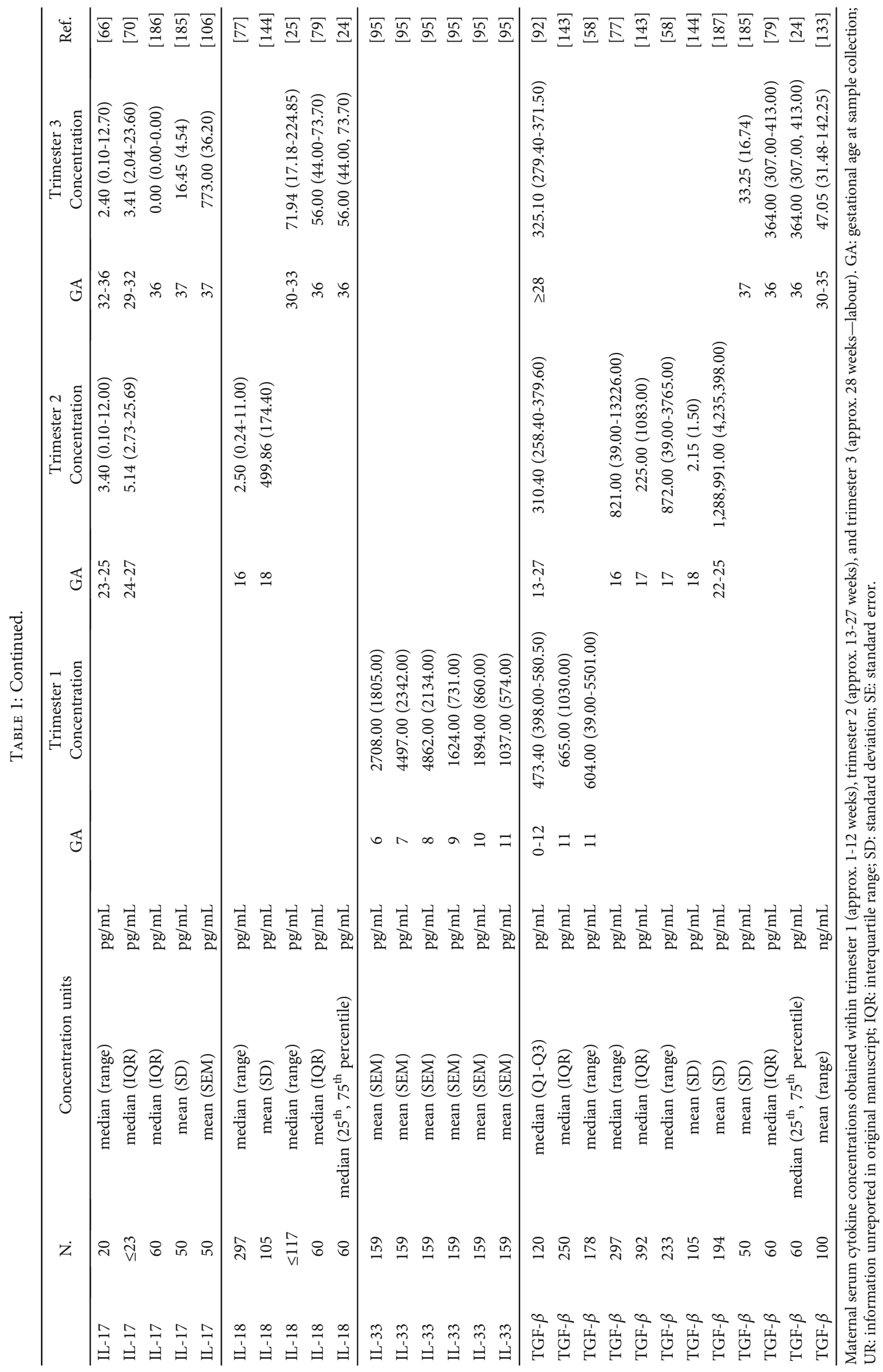




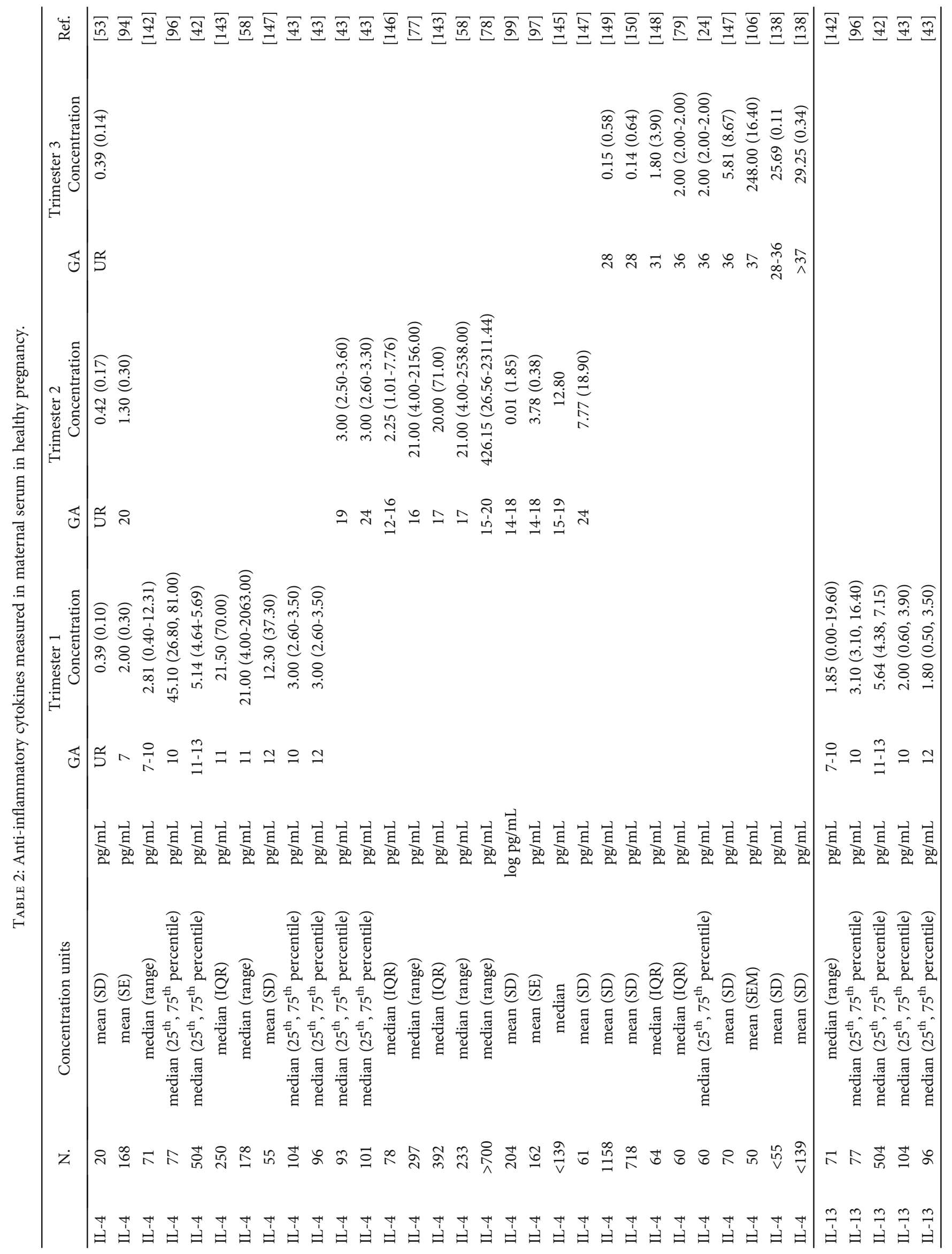




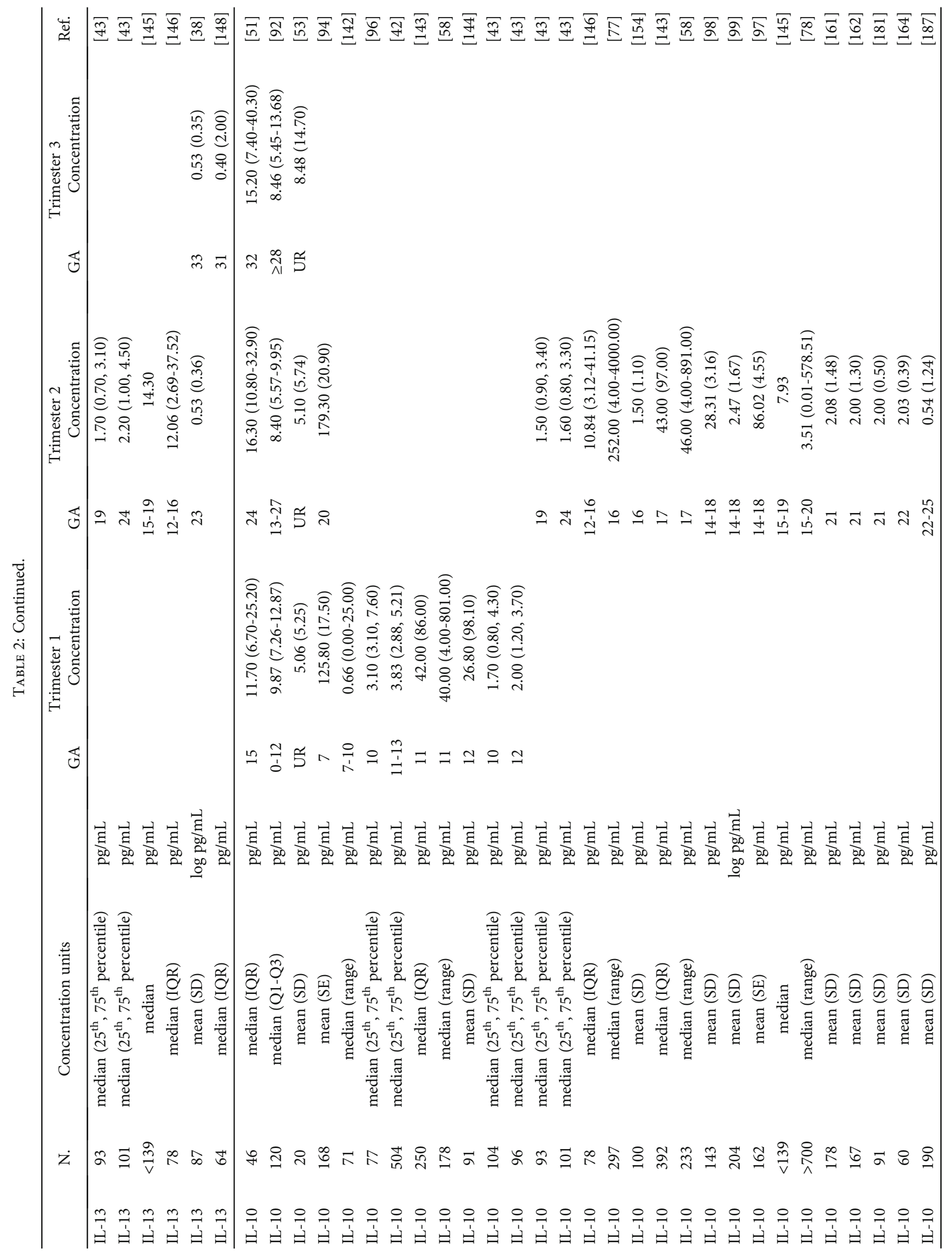




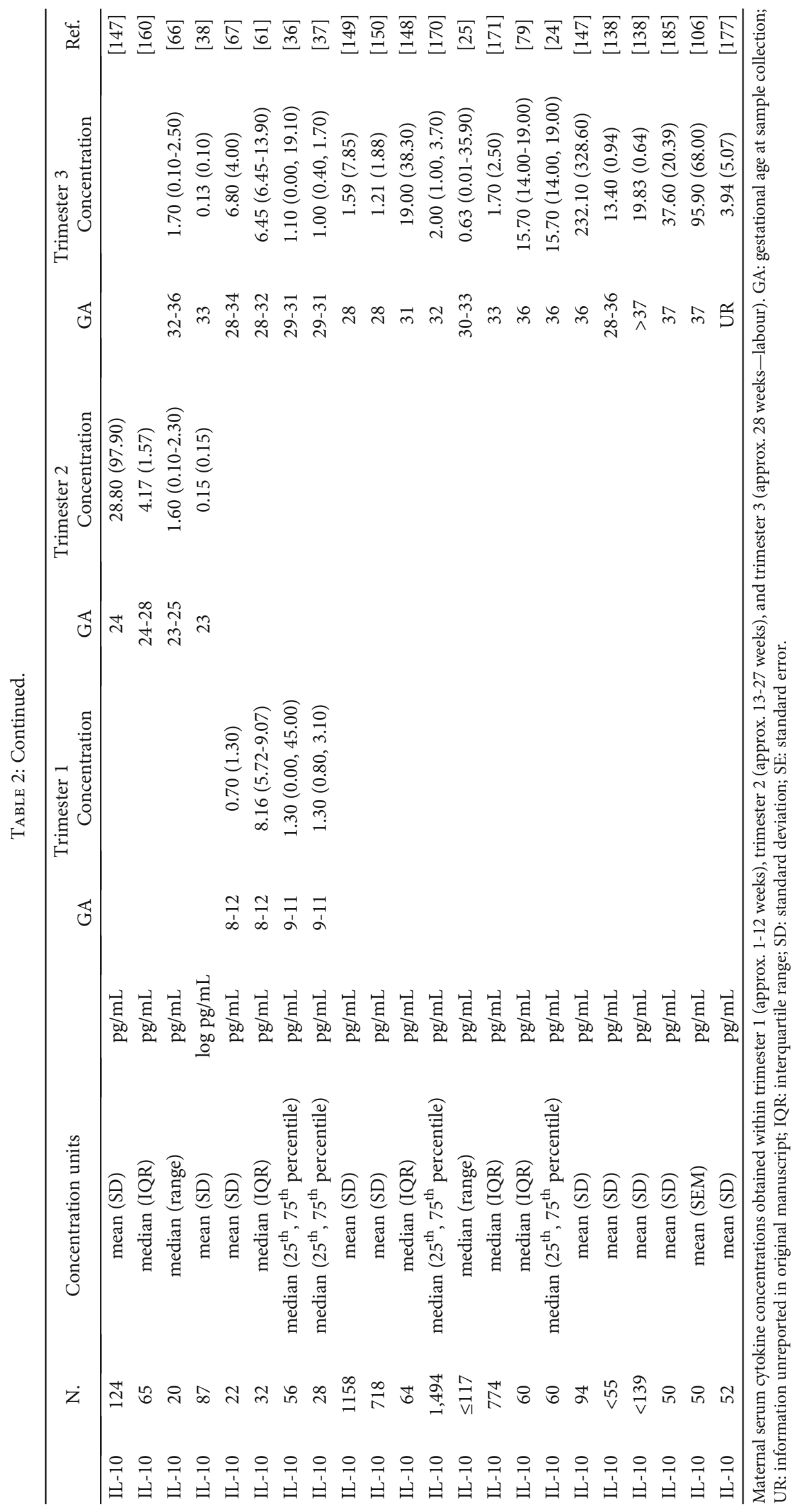




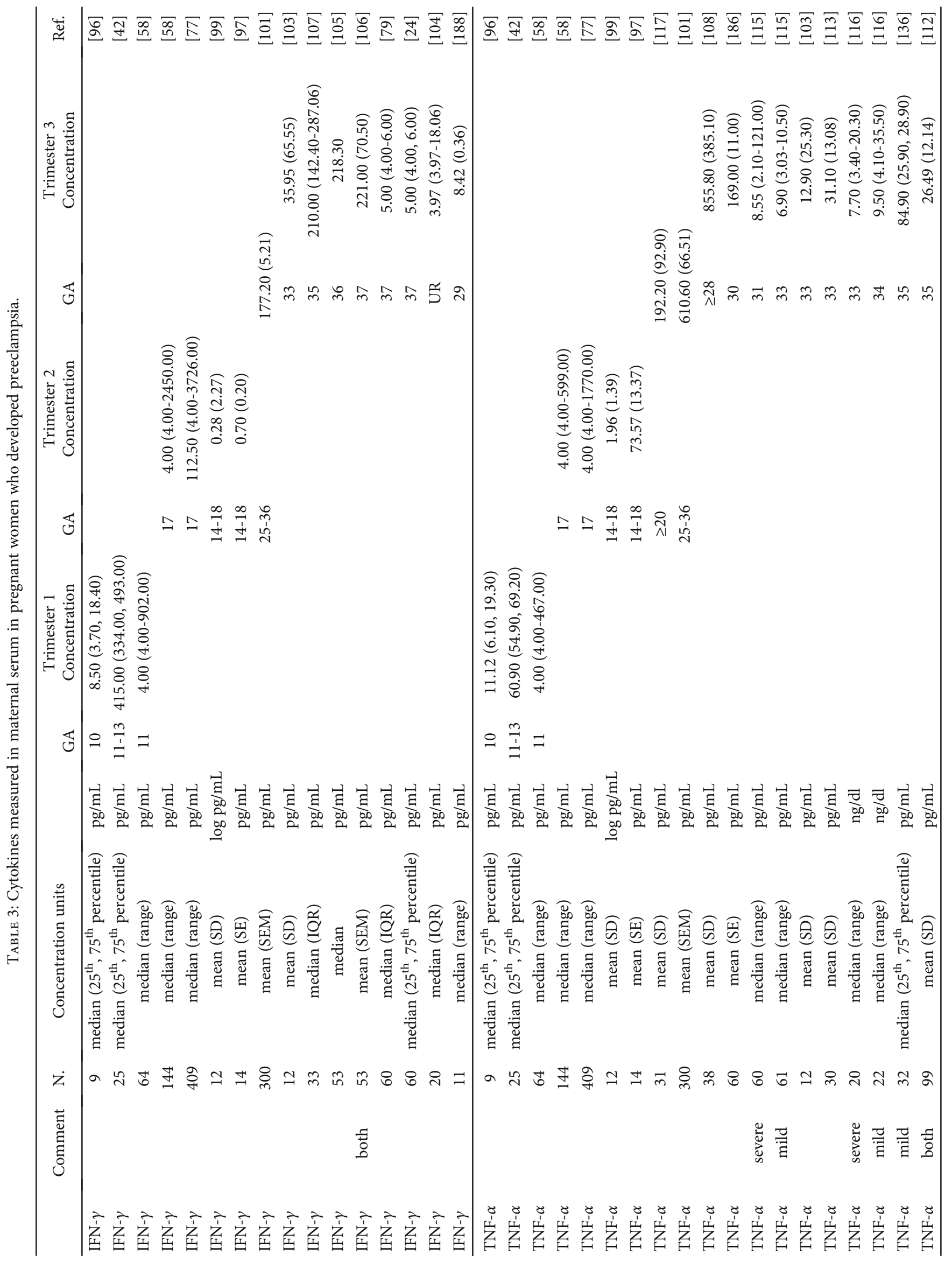




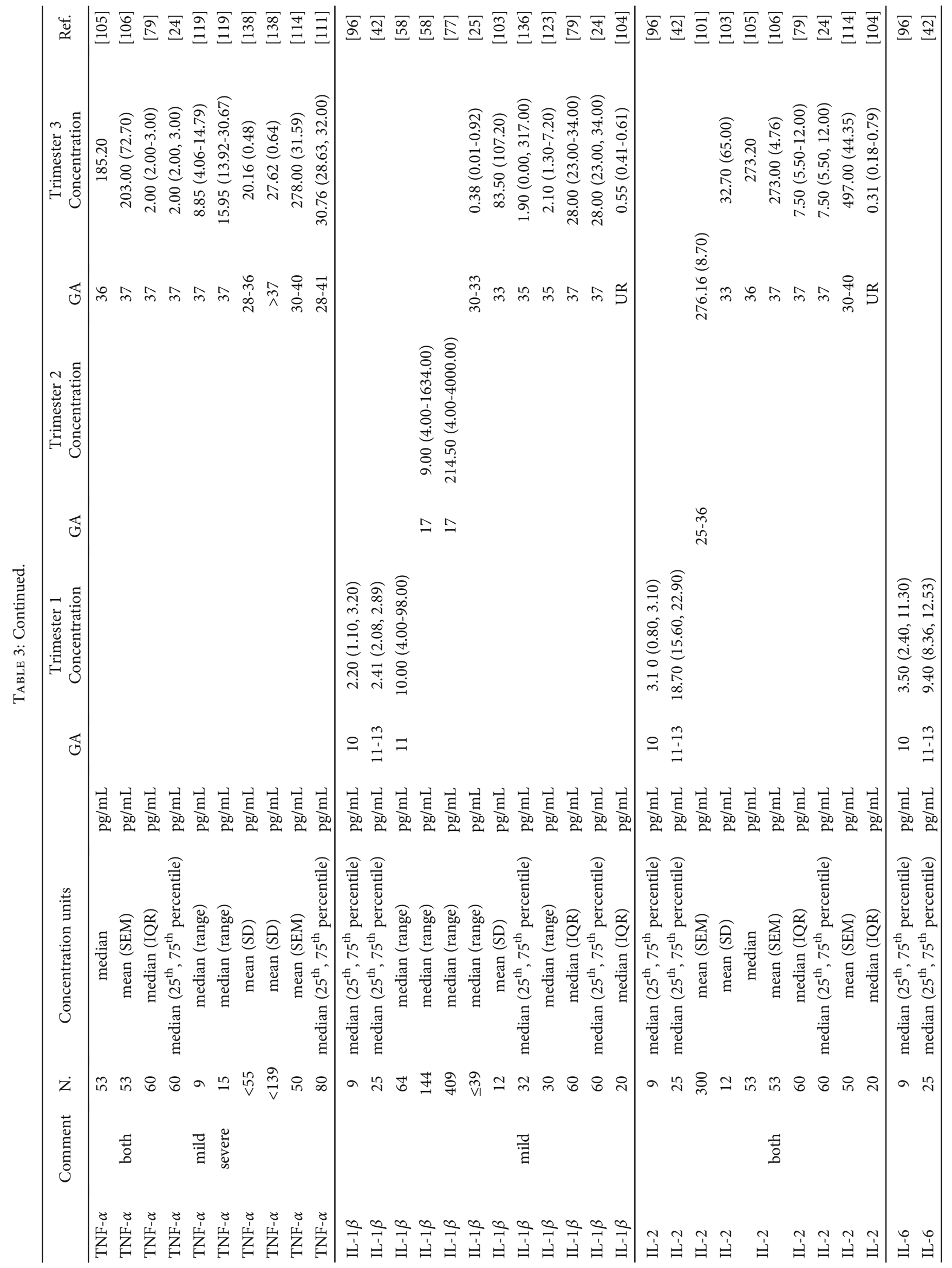




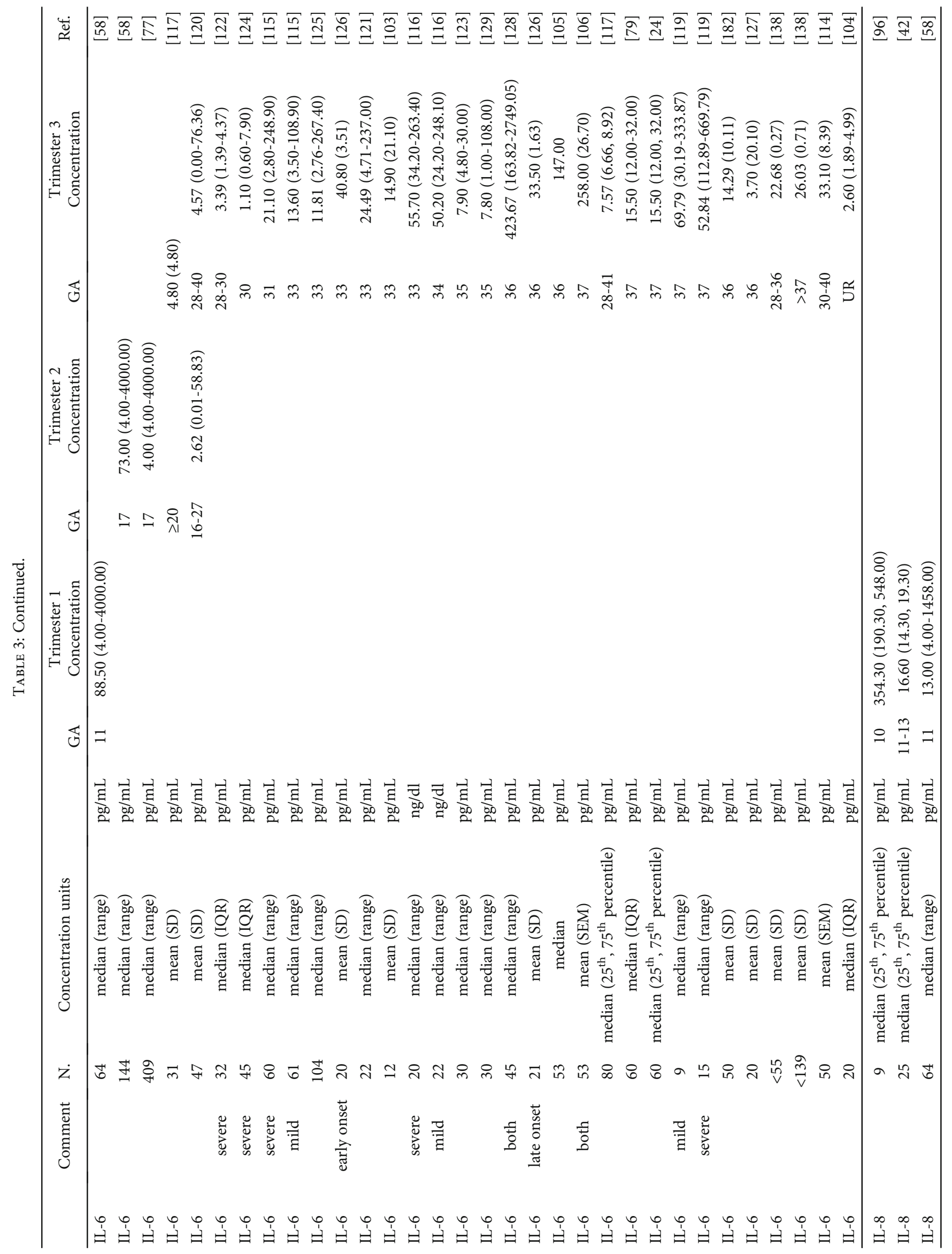




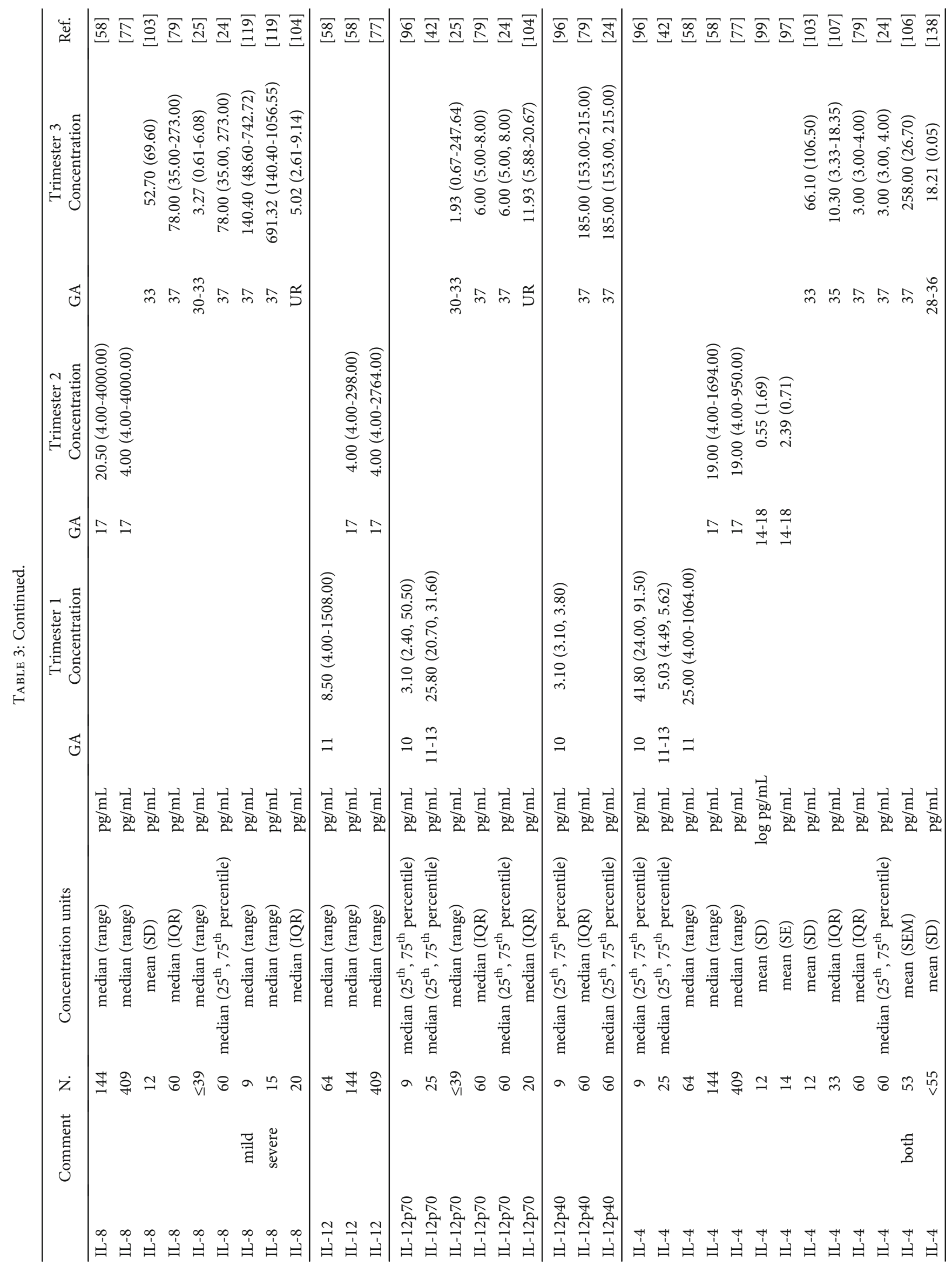




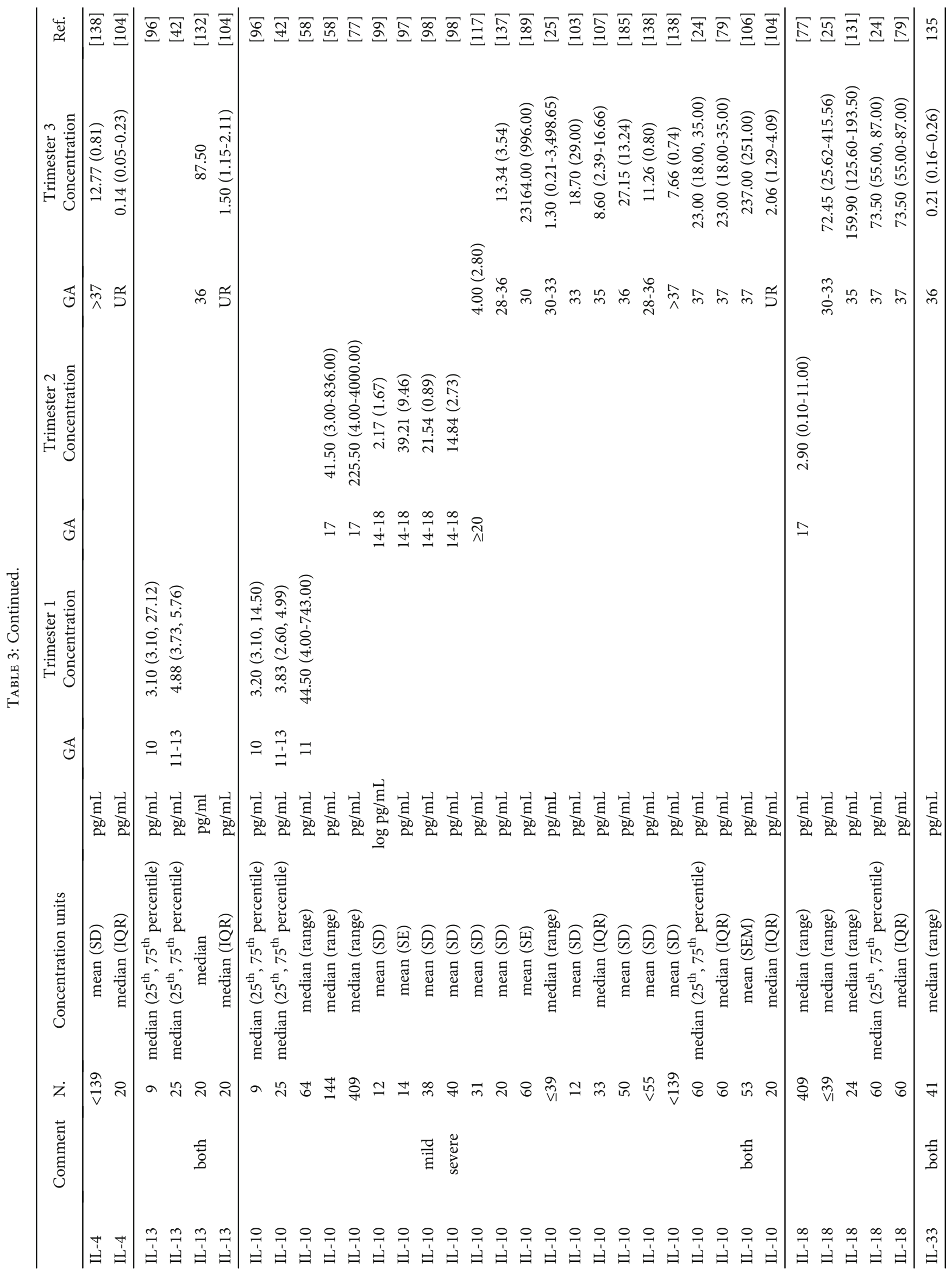




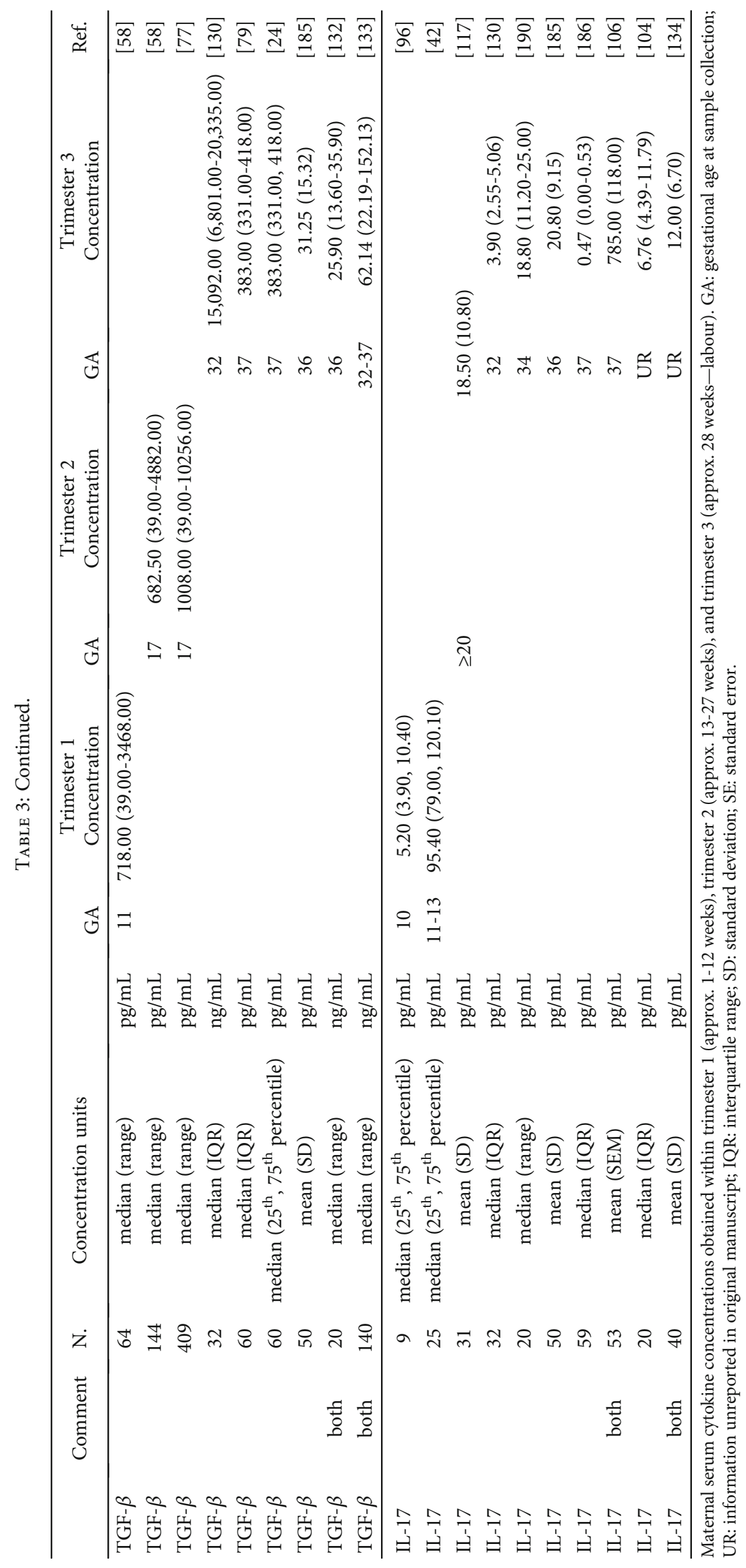


several studies in this review found that IL-6 concentrations significantly increase during healthy pregnancy, others reported no significant change $[36,38,55,56,61,67-70]$.

Th17 cells are important for coordinating innate and adaptive immune responses against invading pathogens and are involved in the development of autoimmunity. IL-17 (IL-17A) and IL-17F are better understood compared to other members of the IL-17 cytokine family. IL-17 cytokines are secreted by Th17 cells and promote production of other proinflammatory cytokines which, if unregulated, 5 can contribute to the development of autoimmune conditions [71]. One study reported that IL-17 concentrations significantly increase with gestation; however, IL-17 was detected in all three trimesters in only three out of 13 women [72], indicating that serum IL-17 may be difficult to detect in healthy pregnancy. A larger study found that IL-17 concentrations significantly decrease between the first and second trimesters of healthy pregnancy [43]. Meanwhile, data from another cohort showed significant variation in IL-17 concentrations across 5 time points throughout healthy pregnancy but reported no "obvious trend" [73]. Owing to few studies measuring maternal serum IL-17 at multiple time points, there is not enough data to understand specific changes during healthy pregnancy. Although not within the scope of this review, recent research examined the importance of the "Th17/Treg" paradigm in pregnancy, whereby the altered Th17:Treg ratio (reduced Treg cells) may contribute to preeclampsia [16].

Interleukin-1 beta (IL-1 $\beta$ ) is similar in structure and function to IL- $1 \alpha$, and both proteins are encoded by genes located on chromosome 2 and act through binding to the type 1 IL-1 receptor (IL-1R1) to elicit proinflammatory responses [74]. In response to stimuli, including DAMPs or PAMPs, IL- $1 \beta$ is secreted by immune cells including monocytes and macrophages [75]. IL- $1 \beta$ is a Th1 cytokine but is also associated with Th17 responses [76]. Existing data suggests that IL- $1 \beta$ is typically present at low concentrations in maternal serum during healthy pregnancy with fewer studies detecting concentrations above $10 \mathrm{pg} / \mathrm{mL}$ [24, 41, 51, 77-79]. A study showed that IL- $1 \beta$ is significantly higher in maternal serum within the second and third trimesters compared to the first [51], while others indicate that IL- $1 \beta$ significantly decreases between the first and third trimester [36, 37]. In contrast, there is also data supporting no significant change in maternal serum IL- $1 \beta$ concentrations across various time points of healthy pregnancy $[43,56]$. Such conflicting results may be explained by difficulty in detecting significant changes in IL- $1 \beta$ because of its short half-life in circulation $[75,80]$.

The proinflammatory cytokine, interleukin-2 (IL-2), acts by binding to the IL-2R, influencing T lymphocyte differentiation into effector and memory $\mathrm{T}$ cells as well as regulatory $\mathrm{T}$ cells which are important for preventing autoimmunity [81]. Evidence suggests that there is a significant reduction in maternal serum IL-2 concentrations between the first and third trimester of healthy pregnancy $[36,37]$. The existing data on maternal serum IL-2 concentrations is limited and may be owing to difficulty in detecting the cytokine in healthy pregnancy as studies have noted concentrations below the lower limit of detection (<LLOD) [25, 66, 82]. IL-2 does not appear to be present at high concentrations in healthy pregnancy but is elevated in women who develop complications including preeclampsia [83] which is discussed in more detail later in this review.

The inflammatory chemokine, interleukin-8 (IL-8), signals through binding CXCR1 and CXCR2 to promote recruitment of immune cells such as neutrophils and macrophages to sites of inflammation [84]. IL-8 mediates angiogenesis in vitro [85] which is an important process in pregnancy for fetal development [86]. In healthy pregnancy, IL-8 has been shown to decrease with gestational age during the first half of pregnancy [43] but significantly increase between the second and third trimesters [38]. Another study found higher, albeit nonsignificant, concentrations in the third trimester compared to the second trimester [56]. These changes in IL-8 concentrations may reflect the Th1/Th2 cytokine shift, indicating reduced proinflammatory responses in the second trimester, but the immune profile returns to more proinflammatory responses towards the end of pregnancy. Meanwhile, a study found that IL-8 significantly decreased between the first and third trimesters of healthy pregnancy [36]. While most research has detected significant changes, a smaller study reported no change between the first and third trimesters [37] which may indicate a lack of power within the study design.

IL-12 is a proinflammatory cytokine important in regulating both innate and adaptive immune responses including the differentiation of Th1 cells [87]. Thus, IL-12 plays an important role in the regulation of Th1 immune responses. The IL-12 cytokine consists of two subunits (p35 and p40) encoded by separate genes on chromosomes 3 (IL-12A) and 5 (IL-12B), respectively, and the resulting biologically active heterodimer is IL-12p70 [88]. A significant reduction in maternal serum IL-12 concentrations has been observed between the first and third trimesters of healthy pregnancy $[36,37]$. IL-12p70 concentrations are similar between the first and second trimesters [43] and second and third trimesters [66]. Therefore, IL-12 may be lower in the third trimester compared to the first, but because of limited data as no study measured IL-12 within all three trimesters of healthy pregnancy, specific changes are not well understood.

Interleukin-10 (IL-10), encoded on chromosome one, is an anti-inflammatory cytokine and acts through a receptor complex consisting of IL-10R1 and IL-10R2 [89]. The multifunctional cytokine is produced by macrophages, mast cells, Th2 cells, and regulatory T cells (Tregs) and can inhibit proinflammatory cytokines including IFN- $\gamma$ [90]. IL-10 and TGF- $\beta$ are secreted by Tregs, and their immunomodulatory properties control inflammation which is important for successful pregnancy. Tregs are essential for the maintenance of healthy pregnancy, and IL-10 is known to mediate Treg development [91]. In healthy pregnancy, maternal serum IL-10 concentrations significantly decrease between the first and second trimesters [43] and between the second and third trimesters [38], although the difference in concentration values were subtle. Others reported significantly higher IL10 concentrations in the third trimester compared to the first [51] and second [53]. Notably, there is also evidence of no 
significant change in IL-10 concentrations during healthy pregnancy $[36,61,66,67,92]$. Overall, IL-10 concentrations may increase in the third trimester of healthy pregnancy or remain consistent throughout pregnancy.

IL-4 mediates differentiation of naive $\mathrm{T}$ cells into Th2 cells and acts as an anti-inflammatory cytokine by binding to its receptor, IL-4R $\alpha$, and activating the STAT6 signalling pathway [93]. In healthy pregnancy, maternal serum IL-4 concentrations appear to remain constant throughout gestation $[43,53]$. Others that have measured IL4 did not look for differences in concentrations across pregnancy [94] while some report that IL-4 is below the LLOD in healthy pregnancy $[38,66]$. Although there is limited research, IL-13 $[38,43]$ and IL-33 [95] concentrations also remain consistent during healthy pregnancy. IL-5, IL-7, IL-9, IL-15, and IL-31 were not discussed in this review due to limited data and/or did not appear to have a relevant role in healthy pregnancy or preeclampsia.

\section{Serum Cytokines as Early Biomarkers of Preeclampsia}

There is increasing interest in the role of cytokines as early biomarkers of preeclampsia. Studies have measured maternal serum cytokines in samples collected prior to the onset of preeclampsia and examined the difference between women who later developed preeclampsia and women who remained healthy. For TNF- $\alpha$, while evidence suggests serum concentrations do not significantly differ between those who later developed preeclampsia and women who remained healthy $[42,58,77,96]$, others report that TNF- $\alpha$ measured at $14-$ 18 weeks may be a potential biomarker for the onset of preeclampsia with lower concentrations of TNF- $\alpha$ observed in women who later developed preeclampsia [97].

In early pregnancy (10-14 weeks), IL- $1 \beta$ significantly differs between women who develop preeclampsia and those who remain healthy (data not in tables as concentration was presented as a multiple of the gestational median value (MoM) ratio) [26]. Furthermore, in maternal samples obtained in the second trimester (approx. 17 weeks), IL-1 $\beta$ is reportedly higher in healthy pregnancy compared to women who developed preeclampsia, with higher IL- $1 \beta$ concentrations in the second trimester associated with decreased odds of developing preeclampsia [58, 77]. On the other hand, first trimester IL- $1 \beta$ concentrations have been linked to preterm birth associated with preeclampsia ( $<37$ weeks) [58], but not with those who only developed preeclampsia [42, $58,96]$. Overall, IL- $1 \beta$ may be an early predictor for preeclampsia resulting in preterm delivery albeit more research is needed.

Research has shown no difference in maternal serum IL8, IL-12, or IL-6 concentrations between women who later developed preeclampsia and women with healthy pregnancy $[42,77]$. In the first trimester, a study found significantly higher serum IL-8 concentrations in women who developed preeclampsia but no difference in IL-12p40, IL-12p70, or IL-6 compared to women with healthy pregnancy [96]. In women who went onto developing preeclampsia, another study found that those with samples collected in the first tri- mester had significantly higher IL-12 and IL-6 concentrations while women with second trimester serum samples had higher IL-8 [58]. From our literature search, there are some data indicating that IL-8, IL-12, and IL-6 may be early predictors for the onset of preeclampsia, but more research would be required to confirm these existing findings.

In samples obtained in the first trimester, some evidence suggests that IL-10 concentrations are significantly higher in women who developed preeclampsia compared to women with healthy pregnancy [65 58], while others indicate no significant difference $[42,96]$. In samples collected in the second trimester, IL-10 is significantly lower in women who later develop preeclampsia compared to women who remain healthy $[58,77,97,98]$. Furthermore, mean IL-10 concentrations at 14-18 weeks are also significantly lower in women who developed severe preeclampsia $(21.54 \mathrm{pg} / \mathrm{mL})$ compared to women with mild preeclampsia $(14.84 \mathrm{pg} / \mathrm{mL})$ [98]. Another study, however, reported no difference in IL-10 at 14-18 weeks between women who later developed preeclampsia and women who did not [99]. Most studies which reported significant differences had larger cohorts with $>50$ women who developed preeclampsia $[58,77,98]$, while studies that reported no significance consisted of $<15$ women in the preeclampsia group $[49,96,99]$. It may be important to consider differences in power between these studies. Overall, several studies suggest that lower IL-10 concentrations in the second trimester (14-18 weeks) may be an early predictor for the onset of preeclampsia.

IL-18 concentrations in the second trimester are higher in women who develop preeclampsia compared to controls [77]. Maternal serum TGF- $\beta$ concentrations in the first [58] and second [77] trimesters are higher in women who developed preeclampsia compared to controls. In contrast, another study found that women who developed preeclampsia had lower TGF- $\beta$ concentrations in the second trimester which was significantly associated with preeclampsia [58]. This observation aligns with the studies previously mentioned that reported significantly lower IL-10 concentrations in women who later developed preeclampsia [58, 77, 97, 98], which may reflect the dual importance of Treg cytokines IL10 and TGF- $\beta$ in successful pregnancy. It is important to consider limitations associated with measuring TGF- $\beta$ in serum as platelets have a large amount of TGF- $\beta$ in their granules [100]; when serum is obtained without anticoagulant platelet, degranulation may occur and result in higher concentrations of TGF- $\beta$. Overall, lower maternal serum IL-10 concentrations in the second trimester may be associated with the onset of preeclampsia, which may reflect the importance of anti-inflammatory and Treg cytokines in controlling inflammation midgestation.

\section{Cytokines in Preeclampsia}

Cytokines are frequently measured within the third trimester for comparison between women suffering from preeclampsia and healthy pregnant controls. Several studies reported significantly higher IFN- $\gamma$ concentrations in preeclampsia compared to healthy pregnancy $[24,79,101]$. Increased IFN- $\gamma$ concentrations in preeclampsia may reflect increased viral 
immune responses or natural killer cell activity, as infection is associated with preeclampsia [102] and could subsequently result in the promotion of proinflammatory pathways and pregnancy complications. Others, however, found significantly lower IFN- $\gamma$ concentrations in women with preeclampsia [103] or no significant difference between preeclampsia and healthy pregnant women [104-107]. From the literature discussed in this review, the larger studies found significantly higher IFN- $\gamma$ concentrations [24, 79, 101] and it is likely that IFN- $\gamma$ is elevated during the third trimester in women with preeclampsia compared to healthy pregnant women. The largest study found significantly higher concentrations, but their study design consisted of a wider sampling time period (25-36 weeks) [101].

In the third trimester, several studies report significantly higher maternal serum TNF- $\alpha$ concentrations in women with preeclampsia compared to controls [24, 101, 108-115] while others have detected similar or nonsignificantly different concentrations $[103,105,106,116]$. Variation in study design may have contributed to the differences in findings, for example, sample size, methodology used to measure cytokine concentrations, and exclusion criteria (including maternal infection, preexisting or subclinical illnesses, and smoking). Studies indicating no significant difference in TNF- $\alpha$ concentrations between preeclampsia and healthy pregnancy had smaller cohorts ( $<40$ participants) [103, 116] than most studies showing that TNF- $\alpha$ is significantly higher in preeclampsia ( $\geq 40$ participants) $[24,101,109-$ 112]. The largest study we identified showed higher TNF- $\alpha$ concentrations in women with preeclampsia $(n=300)$ than in healthy controls $(n=200)$ excluding smokers and those with urinary or respiratory infections [101], while others who did not find significant differences did not state if they controlled for these factors [103, 105]. Another study observed lower, but not statistically significant, serum TNF$\alpha$ concentrations in women with preeclampsia compared to women with healthy pregnancy at $\geq 20$ weeks [117]. The study consisted of a small sample size (healthy $n=24$ and preeclampsia $n=31$ ) and, as the sampling period crossed between the second and third trimesters, it may have been important to stratify participants by mild/severe- or early/late-onset preeclampsia. Overall, most work indicates that TNF- $\alpha$ concentrations are higher in preeclampsia compared to healthy pregnant women, reflecting the enhanced proinflammatory systemic environment.

Maternal serum IL-2 concentrations are significantly higher in preeclampsia compared to healthy pregnant women $[24,79,101,114]$. Elevated IL-2 concentrations may reflect the proinflammatory environment associated with preeclampsia. Research using a murine model of placental ischemia in pregnancy proposed that IL-2 is a key cytokine mediating natural killer cell activation and placental health in preeclampsia [118]. Others, however, reported no difference in IL-2 concentrations between preeclampsia and healthy pregnancy [103-106].

Multiple studies observed significantly higher IL-8 concentrations in preeclampsia compared to healthy pregnancy $[24,79,104,119]$, while others report no significant difference $[25,103]$. Inconsistent findings may be owing to the sampling time point as those who did not find a significant difference collected samples earlier (30-33 weeks) [25, 103] than 37 weeks $[24,79,119]$. Most evidence indicates higher IL-6 concentrations in preeclampsia compared to healthy pregnancy $[24,79,104,111,114,115,119-126]$, while data from other studies show no difference between the two groups [103, 105, 106, 116, 117, 127-129]. From the studies examined in this review, those consisting of larger cohorts have shown significantly higher IL- 6 concentrations in preeclampsia compared to controls [24, 79, 111, 115, 125]. Nonetheless, most evidence suggests that IL- 8 and IL-6 are higher in preeclampsia compared to healthy pregnant women and may be as a result of preeclampsia.

Research suggests that IL-12p40, IL-12p70 [24, 79], IL-17 $[104,130]$, IL- $18[24,79,131]$, and TGF- $\beta[132,133]$ are elevated in women with preeclampsia in the third trimester compared to healthy controls. Others, however, have found no difference in IL-12p70 [25, 104], IL-17 [117, 134], and TGF- $\beta[24,79]$ in women with preeclampsia compared to controls. In contrast, maternal serum TGF- $\beta$ concentrations are reportedly lower in women with preeclampsia with fetal growth restriction compared to controls [130]. One study reported significantly lower IL-33 concentrations in women with preeclampsia compared to healthy pregnancy in the third trimester [135]. With limited data for these cytokines, more research is required to understand their importance in preeclampsia.

IL- $\beta[24,79,103,110,136]$, IL-4 $[103,104,106,107]$, and IL-13 [104, 132] do not appear to significantly contribute to the pathogenesis of preeclampsia as most research examined in this review indicated no difference in these cytokine concentrations between preeclampsia and healthy pregnancy in the third trimester. Others, however, reported that IL- $1 \beta$ was significantly higher $[104,123]$ or lower [25] in women with preeclampsia. Furthermore, other studies suggest that IL- 4 is significantly higher in preeclampsia compared to healthy pregnancy [24, 79]. In preeclampsia, the proinflammatory: anti-inflammatory ratio (IL-2: IL-4 and IFN- $\gamma$ :IL-4) is elevated compared to healthy pregnant controls [24], reflecting the more proinflammatory response associated with preeclampsia.

In the third trimester, most studies reported no significant change in maternal serum IL-10 concentrations between women with preeclampsia and healthy pregnancy $[25,97,103,104,106,117]$. In contrast, others have detected significantly higher IL-10 concentrations in preeclampsia compared to healthy pregnant women $[24,79$, 107]. As preeclampsia is deemed a more proinflammatory environment, IL-10 concentrations may be raised in response to the inflammatory environment. Another study showed significantly lower IL-10 concentrations in women with preeclampsia compared to controls in the third trimester $[137,138]$. As IL-10 is a key cytokine in the regulation of inflammation, lower IL-10 concentrations in women with preeclampsia may suggest that IL-10 is not effectively controlling the proinflammatory environment that occurs during preeclampsia.

Although beyond the scope of this review, the placenta is a key organ contributing to the inflammatory milieu during pregnancy and immune tolerance. Regulation of immune 


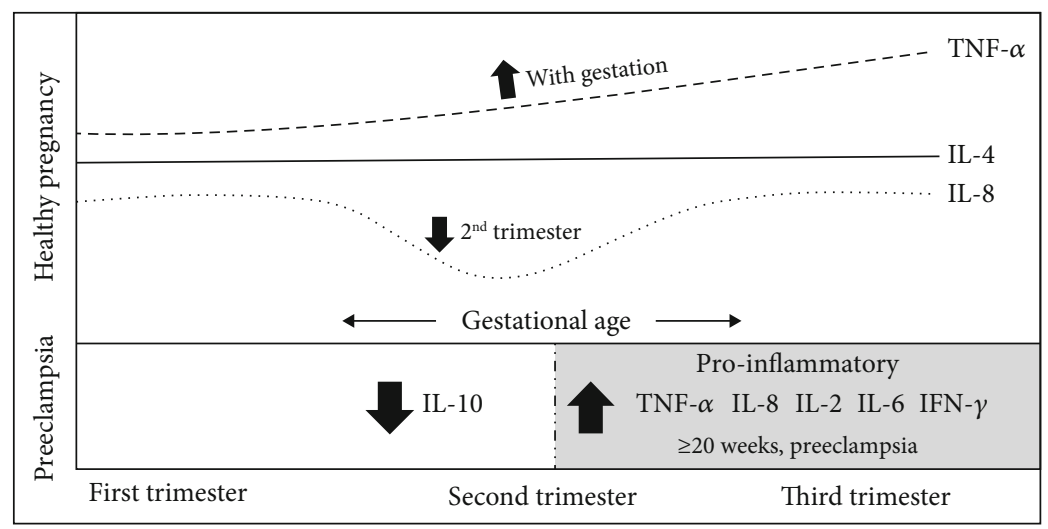

FIGURE 2: An illustration summarising the changes in the maternal serum cytokine profile in healthy pregnancy and preeclampsia.

interactions at the maternal-fetal interface is essential, and the placenta microenvironment is biased towards Th2 [139]. Abnormal placenta development is a key factor in the pathogenesis of preeclampsia $[140,141]$. It is important to consider that, in preeclampsia, there are increased proinflammatory cytokines in both the maternal circulation and the placenta $[17,138]$.

\section{Summary of Findings}

We found substantial evidence of changes in cytokine concentrations that occur during healthy pregnancy. Figure 2 illustrates the main findings of this review. It is likely that TNF- $\alpha$ increases as pregnancy progresses, IL- 8 decreases in the second trimester, and IL- 4 concentrations remain consistent throughout gestation. IFN- $\gamma$ and IL-17 did not appear to have an obvious trend in cytokine concentrations. We found inconsistent or not enough data to specify changes in the remaining cytokines. Lower IL-10 concentrations in early pregnancy may be associated with the later development of preeclampsia, but data collected later in pregnancy were inconsistent. Therefore, it may be important to measure IL10 in early pregnancy as a predictor of the development of preeclampsia. Most proinflammatory cytokines, particularly TNF- $\alpha$, IFN- $\gamma$, IL-2, IL- 8 , and IL-6, are significantly higher in women suffering from preeclampsia compared to women with healthy pregnancy reflecting the enhanced proinflammatory environment.

\section{Strengths and Limitations}

This review was conducted with a systematic approach and covered a large number of research studies in this area. For decades, cytokines have been frequently measured in peripheral maternal samples to examine the immune response. This review provides a summary of the current maternal serum cytokine data, allowing for easy comparison of cytokine concentrations across studies. Limitations of this review were excluding data collected prior to 2009 , studies consisting of $<50$ healthy pregnant women, and cytokines measured in other biological samples. Comparability of data between studies may be limited by differences in study design including varying methods used to detect cytokine concentrations with different specificity and sensitivity limits (ELISA vs. multiplex immunoassays), sample collection, sample storage conditions, and duration.

\section{Future Directions}

Although maternal serum cytokine concentrations have been measured in numerous cohorts, we found limited data for several cytokines. Many studies obtained samples at one or two trimesters of pregnancy which limited our ability to determine change across healthy gestation for many cytokines. As cytokines are a network of signalling proteins which influence each other as well as their target cells, obtaining a range of biological samples at multiple time points across healthy gestation will allow for in-depth analysis on changes in maternal cytokine concentrations. In future, more sensitive methods, e.g., flow cytometry analysis, may be used alongside peripheral cytokine assays to provide a better indication of cell subtypes and intracellular cytokine expression. It may also be useful to examine further if IL-10 measured in early pregnancy is a good predictor for the development of preeclampsia.

\section{Abbreviations \\ IL: Interleukin \\ TNF: Tumour necrosis factor \\ IFN: Interferon \\ TGF: Transforming growth factor \\ Tregs: Regulatory T cells \\ Th: T helper cells.}

\section{Data Availability}

The cytokine concentration data supporting this comprehensive review are from previously reported studies which have been cited. No new data was derived from this study.

\section{Conflicts of Interest}

The authors declare that they have no conflict of interests. 


\section{Acknowledgments}

The authors thank the Department for the Economy (DfE) for the $\mathrm{PhD}$ studentship funding.

\section{Supplementary Materials}

Supplementary Table 1 outlines key concepts of the literature search conducted on Ovid/Medline databases. (Supplementary Materials)

\section{References}

[1] G. Mor, I. Cardenas, V. Abrahams, and S. Guller, "Inflammation and pregnancy: the role of the immune system at the implantation site," Annals of the New York Academy of Sciences, vol. 1221, no. 1, pp. 80-87, 2011.

[2] S. S. Morelli, M. Mandal, L. T. Goldsmith, B. N. Kashani, and N. M. Ponzio, "The maternal immune system during pregnancy and its influence on fetal development," Research and Reports in Biology, vol. 2015, pp. 171-189, 2015.

[3] P. D. Medawar, "Some immunological and endocrinological problems raised by the evolution of viviparity in vertebrates," Symposium of the Society for Experimental Biology, vol. 7, pp. 320-328, 1953.

[4] S. Guller and L. LaChapelle, "The role of placental Fas ligand in maintaining immune privilege at maternal-fetal interfaces," Seminars in Reproductive Endocrinology, vol. 17, no. 1, pp. 39-44, 1999.

[5] C. A. Koch and J. L. Platt, "T cell recognition and immunity in the fetus and mother," Cellular Immunology, vol. 248, no. 1, pp. 12-17, 2007.

[6] G. Mor, Immunology of Pregnancy, Springer-Verlag, New York, 2006.

[7] L. Sykes, D. A. MacIntyre, X. J. Yap, G. T. Tiong, and P. R. Bennett, "The Th1:Th2 dichotomy of pregnancy and preterm labour," Mediators of Inflammation, vol. 2012, 12 pages, 2012.

[8] I. F. Reijnders, A. G. M. G. J. Mulders, and M. P. H. Koster, "Placental development and function in women with a history of placenta-related complications: a systematic review," Acta Obstetricia et Gynecologica Scandinavica, vol. 97, pp. 248-257, 2018.

[9] S. A. Robertson, A. S. Care, and L. M. Moldenhauer, "Regulatory $\mathrm{T}$ cells in embryo implantation and the immune response to pregnancy," The Journal of Clinical Investigation, vol. 128, pp. 4224-4235, 2018.

[10] T. G. Wegmann, H. Lin, L. Guilbert, and T. R. Mosmann, "Bidirectional cytokine interactions in the maternal-fetal relationship: is successful pregnancy a TH2 phenomenon?," Trends in Immunology, vol. 14, pp. 353-356, 1993.

[11] G. Reinhard, A. Noll, A. V. Ruecker, H. Schlebusch, and P. Mallmann, "Shifts in the TH1/TH2 balance during human pregnancy correlate with apoptotic changes," Biochemical and Biophysical Research Communications, vol. 245, pp. 933-938, 1998.

[12] G. Mor and I. Cardenas, "The immune system in pregnancy: a unique complexity," American Journal of Reproductive Immunology, vol. 63, pp. 425-433, 2010.

[13] D. C. Arikan, A. Coskun, M. Aral, and A. Ozer, "Plasma IL-4, IL-8, IL-12, interferon- $\gamma$ and CRP levels in pregnant women with preeclampsia, and their relation with severity of disease and fetal birth weight," The Journal of Maternal-Fetal \& Neonatal Medicine, vol. 25, pp. 1569-1573, 2012.

[14] M. B. Pinheiro, O. Martins-Filho, A. P. L. Mota et al., "Severe preeclampsia goes along with a cytokine network disturbance towards a systemic inflammatory state," Cytokine, vol. 62, pp. 165-173, 2013.

[15] C. La Rocca, F. Carbone, S. Longobardi, and G. Matarese, "The immunology of pregnancy: regulatory T cells control maternal immune tolerance toward the fetus," Immunology Letters, vol. 162, pp. 41-48, 2014.

[16] A. S. Figueiredo and A. Schumacher, "The T helper type 17/regulatory T cell paradigm in pregnancy," Immunology, vol. 148, pp. 13-21, 2016.

[17] D. C. Cornelius, "Preeclampsia: from inflammation to immunoregulation," Clinical medicine insights: Blood disorders, vol. 11, 2018.

[18] P. Rudra, S. Basak, D. Patil, and M. Y. Latoo, "Recent advances in management of pre-eclampsia," BJMP, vol. 4, p. a433, 2011.

[19] M. A. Brown, L. A. Magee, L. C. Kenny et al., "The hypertensive disorders of pregnancy: ISSHP classification, diagnosis \& management recommendations for international practice," Pregnancy Hypertens, vol. 13, pp. 291-310, 2018.

[20] N. Khan, W. Andrade, H. De Castro, K. H. Nicolaides, A. Wright, and D. Wright, "Impact of new definitions of pre-eclampsia on incidence and performance of firsttrimester screening," Ultrasound in Obstetrics \& Gynecology, vol. 55, pp. 50-57, 2020.

[21] R. A. Ødegård, L. J. Vatten, S. T. Nilsen, K. Å. Salvesen, and R. Austgulen, "Preeclampsia and fetal growth," Obstetrics and Gynecology, vol. 96, pp. 950-955, 2000.

[22] A. C. Harmon, D. C. Cornelius, L. M. Amaral et al., "The role of inflammation in the pathology of preeclampsia," Clinical Science, vol. 130, pp. 409-419, 2016.

[23] Y. Jonsson, M. Rubèr, L. Matthiesen et al., "Cytokine mapping of sera from women with preeclampsia and normal pregnancies," Journal of Reproductive Immunology, vol. 70, pp. 83-91, 2006.

[24] A. Szarka, J. Rigó Jr., L. Lázár, A. Molvarec, and G. Beko, "Circulating cytokines, chemokines and adhesion molecules in normal pregnancy and preeclampsia determined by multiplex suspension array," BMC Immunology, vol. 11, 2010.

[25] B. Mosimann, M. Wagner, L. C. Y. Poon, K. H. Nicolaides, and A. S. Bansal, "Maternal serum cytokines at 30-33 weeks in the prediction of preeclampsia," Prenatal Diagnosis, vol. 33, pp. 823-830, 2013.

[26] J. E. Siljee, E. J. Wortelboer, M. P. H. Koster et al., "Identification of interleukin-1 beta, but no other inflammatory proteins, as an early onset pre-eclampsia biomarker in first trimester serum by bead-based multiplexed immunoassays," Prenatal Diagnosis, vol. 33, pp. 1183-1188, 2013.

[27] N. J. Hannan, K. Bambang, T. J. Kaitu'u-Lino, C. K. Justin, and S. Tong, "A bioplex analysis of cytokines and chemokines in first trimester maternal plasma to screen for predictors of miscarriage," PLoS One, vol. 9, article e93320, 2014.

[28] M. Makhseed, R. Raghupathy, F. Azizieh, R. Farhat, N. Hassan, and A. Bandar, "Circulating cytokines and CD30 in normal human pregnancy and recurrent spontaneous abortions," Human Reproduction, vol. 15, pp. 20112017, 2000 . 
[29] T. H. Mogensen, "Pathogen recognition and inflammatory signaling in innate immune defenses," Clinical Microbiology Reviews, vol. 22, p. 240, 2009.

[30] G. Tau and P. Rothman, "Biologic functions of the IFN- $\gamma$ receptors," Allergy, vol. 54, pp. 1233-1251, 1999.

[31] B. Parra, C. C. Bergmann, S. A. Stohlman et al., "IFN- $\gamma$ is required for viral clearance from central nervous system oligodendroglia," Journal of Immunology, vol. 162, pp. 16411647, 1999.

[32] D. A. Chesler and C. S. Reiss, "The role of IFN- $\gamma$ in immune responses to viral infections of the central nervous system," Cytokine \& Growth Factor Reviews, vol. 13, pp. 441-454, 2002.

[33] L. Ni and J. Lu, "Interferon gamma in cancer immunotherapy," Cancer Medicine, vol. 7, pp. 4509-4516, 2018.

[34] S. P. Murphy, C. Tayade, A. A. Ashkar, K. Hatta, J. Zhang, and B. A. Croy, "Interferon gamma in successful pregnancies," Biology of Reproduction, vol. 80, pp. 848-859, 2009.

[35] M. Subha, P. Pal, G. K. Pal, S. Habeebullah, C. Adithan, and M. G. Sridhar, "Decreased baroreflex sensitivity is linked to sympathovagal imbalance, low-grade inflammation, and oxidative stress in pregnancy-induced hypertension," Clinical and Experimental Hypertension, vol. 38, pp. 666-672, 2016.

[36] A. Doria, A. Ghirardello, M. Zen et al., "Effect of pregnancy on serum cytokines in SLE patients," Arthritis Research \& Therapy, vol. 14, 2012.

[37] L. Iaccarino, A. Ghirardello, M. Zen et al., "Polarization of Th2 response is decreased during pregnancy in systemic lupus erythematosus," Reumatismo, vol. 64, pp. 314-320, 2012.

[38] K. M. Ross, G. Miller, A. K. K. Leigh et al., "Patterns of peripheral cytokine expression during pregnancy in two cohorts and associations with inflammatory markers in cord blood," American Journal of Reproductive Immunology, vol. 76, pp. 406-414, 2016.

[39] M. Nayak, M. E. W. Eekhoff, M. Peinhaupt, A. Heinemann, G. Desoye, and M. N. M. van Poppel, "Cytokines and their association with insulin resistance in obese pregnant women with different levels of physical activity," Cytokine, vol. 77, pp. 72-78, 2016.

[40] F. M. Schmidt, J. Weschenfelder, C. Sander et al., "Inflammatory cytokines in general and central obesity and modulating effects of physical activity," PLOS ONE, vol. 10, article e0121971, 2015.

[41] E. Protonotariou, C. Chrelias, D. Kassanos, H. Kapsambeli, E. Trakakis, and A. Sarandakou, "Immune response parameters during labor and early neonatal life," In Vivo, vol. 24, pp. 117-124, 2010.

[42] L. H. Tangerås, M. Austdal, R. B. Skråstad et al., "Distinct first trimester cytokine profiles for gestational hypertension and preeclampsia," Arteriosclerosis, Thrombosis, and Vascular Biology, vol. 35, pp. 2478-2485, 2015.

[43] L. M. T. Stokkeland, G. F. Giskeødegård, S. Stridsklev et al., "Serum cytokine patterns in first half of pregnancy," Cytokine, vol. 119, pp. 188-196, 2019.

[44] J. Alijotas-Reig, E. Esteve-Valverde, R. Ferrer-Oliveras, E. Llurba, and J. M. Gris, "Tumor necrosis factor-alpha and pregnancy: focus on biologics. An updated and comprehensive review," Clinical Reviews in Allergy and Immunology, vol. 53, pp. 40-53, 2017.
[45] J. P. Waters, J. S. Pober, and J. R. Bradley, “Tumour necrosis factor in infectious disease," The Journal of Pathology, vol. 230, pp. 132-147, 2013.

[46] J. Radeff-Huang, T. M. Seasholtz, J. W. Chang, J. M. Smith, C. T. Walsh, and J. H. Brown, "Tumor necrosis factor- $\alpha$ stimulated cell proliferation is mediated through sphingosine kinase-dependent Akt activation and cyclin D expression," The Journal of Biological Chemistry, vol. 282, pp. 863-870, 2007.

[47] V. Baud and M. Karin, "Signal transduction by tumor necrosis factor and its relatives," Trends in Cell Biology, vol. 11, pp. 372-377, 2001.

[48] P. De Cesaris, D. Starace, A. Riccioli, F. Padula, A. Filippini, and E. Ziparo, "Tumor necrosis factor-alpha induces interleukin- 6 production and integrin ligand expression by distinct transduction pathways," The Journal of Biological Chemistry, vol. 273, pp. 7566-7571, 1998.

[49] S. Straszewski-Chavez, V. M. Abrahams, and G. Mor, "The role of apoptosis in the regulation of trophoblast survival and differentiation during pregnancy," Endocrine Reviews, vol. 26, pp. 877-897, 2005.

[50] J. B. Moreli, A. M. C. Ruocco, J. M. Vernini, M. V. C. Rudge, and I. M. P. Calderon, "Interleukin 10 and tumor necrosis factor-alpha in pregnancy: aspects of interest in clinical obstetrics," International Scholarly Research Notices, vol. 2012, 5 pages, 2012.

[51] M. Nayak, M. Peinhaupt, A. Heinemann et al., "Sedentary behavior in obese pregnant women is associated with inflammatory markers and lipid profile but not with glucose metabolism," Cytokine, vol. 88, pp. 91-98, 2016.

[52] K. L. Lindsay, C. Buss, P. D. Wadhwa, and S. Entringer, "Maternal stress potentiates the effect of an inflammatory diet in pregnancy on maternal concentrations of tumor necrosis factor alpha," Nutrients, vol. 10, 2018.

[53] S. Olimpia, P. Magdalena, P. Tomasz, W. Piotr, and R. Elzbieta, "Changes in the concentration of sHLA-I and selected cytokines in pregnancy complicated by antiphospholipid syndrome," Ginekologia Polska, vol. 82, pp. 354-358, 2011.

[54] R. Azar and D. Mercer, "Mild depressive symptoms are associated with elevated C-reactive protein and proinflammatory cytokine levels during early to midgestation: a prospective pilot study," Journal of Women's Health (2002), vol. 22, pp. 385-389, 2013.

[55] A. M. Mitchell, K. Porter, and L. M. Christian, "Examination of the role of obesity in the association between childhood trauma and inflammation during pregnancy," Health Psychology, vol. 37, pp. 114-124, 2018.

[56] N. Farah, A. E. Hogan, N. O'Connor, M. M. Kennelly, D. O'Shea, and M. J. Turner, "Correlation between maternal inflammatory markers and fetomaternal adiposity," Cytokine, vol. 60, pp. 96-99, 2012.

[57] H. Saarelainen, P. Valtonen, K. Punnonen et al., "Flow mediated vasodilation and circulating concentrations of high sensitive C-reactive protein, interleukin- 6 and tumor necrosis factor- $\alpha$ in normal pregnancy - The Cardiovascular Risk in Young Finns Study," Clinical Physiology and Functional Imaging, vol. 29, pp. 347-352, 2009.

[58] B. D. Taylor, R. B. Ness, M. A. Klebanoff et al., "First and second trimester immune biomarkers in preeclamptic and normotensive women," Pregnancy Hypertens, vol. 6, pp. 388393, 2016. 
[59] E. R. Blackmore, J. A. Moynihan, M. Gilchrist, T. G. O'Connor, E. K. Pressman, and D. R. Rubinow, "Psychiatric symptoms and proinflammatory cytokines in pregnancy," Psychosomatic Medicine, vol. 73, pp. 656-663, 2011.

[60] L. Wang, X. Hu, X. Liu, P. Qian, J. Ge, and B. Tang, "Influence of epidural dexamethasone on maternal temperature and serum cytokine concentration after labor epidural analgesia," International Journal of Gynaecology and Obstetrics, vol. 113, pp. 40-43, 2011.

[61] F. D. O. De Steenwinkel, Y. A. De Man, J. M. W. Hazes et al., "Circulating maternal cytokines influence fetal growth in pregnant women with rheumatoid arthritis," Annals of the Rheumatic Diseases, vol. 72, pp. 1995-2001, 2013.

[62] T. Tanaka, M. Narazaki, and T. Kishimoto, "IL-6 in inflammation, Immunity, and disease," Cold Spring Harbor Perspectives in Biology, vol. 6, p. a016295, 2014.

[63] J. R. Prins, N. Gomez-Lopez, and S. A. Robertson, "Interleukin-6 in pregnancy and gestational disorders," Journal of Reproductive Immunology, vol. 95, pp. 1-14, 2012.

[64] L. Scholaske, C. Buss, P. D. Wadhwa, and S. Entringer, "Acculturation and interleukin (IL)- 6 concentrations across pregnancy among Mexican-American women," Brain, Behavior, and Immunity, vol. 73, pp. 731-735, 2018.

[65] S. Simavli, A. U. Derbent, S. Uysal, and N. O. Turhan, "Hepcidin, iron status, and inflammation variables among healthy pregnant women in the Turkish population," The Journal of Maternal-Fetal \& Neonatal Medicine, vol. 27, pp. 75-79, 2014.

[66] S. Björkander, K. Bremme, J. Persson, R. F. van Vollenhoven, E. Sverremark-Ekström, and U. Holmlund, "Pregnancy-associated inflammatory markers are elevated in pregnant women with systemic lupus erythematosus," Cytokine, vol. 59, pp. 392-399, 2012.

[67] D. S. Atta, S. M. Abdelwahab, I. Tharwat, E. F. Girbash, H. M. Abdeldayem, and R. Ghonaim, "Maternal cytokines and disease severity influence pregnancy outcomes in women with rheumatoid arthritis," The Journal of Maternal-Fetal \& Neonatal Medicine, vol. 29, pp. 3358-3363, 2016.

[68] J. M. Walsh, R. M. Mahony, M. Culliton, M. E. Foley, and F. M. McAuliffe, "Impact of a low glycemic index diet in pregnancy on markers of maternal and fetal metabolism and inflammation," Reproductive Sciences, vol. 21, pp. 13781381, 2014.

[69] E. R. Blackmore, M. A. Gilchrist, T. G. O'Connor, J. A. Moynihan, S. W. Groth, and D. G. Chen, "Depressive symptoms and proinflammatory cytokines across the perinatal period in African American women," Journal of Psychosomatic Obstetrics and Gynaecology, vol. 35, pp. 8-15, 2014.

[70] M. Kuźmicki, J. Pliszka, J. Wilk et al., “The IL-6/IL-6R/sgp130 system and Th17 associated cytokines in patients with gestational diabetes," Endokrynologia Polska, vol. 65, pp. 169-175, 2014.

[71] W. Jin and C. Dong, "IL-17 cytokines in immunity and inflammation," Emerging microbes \& infections, vol. 2, article e60, 2013.

[72] E. A. Martínez-García, L. Núñez-Atahualpa, B. T. MartínMáquez et al., "IL-17 increased in the third trimester in healthy women with term labor," American Journal of Reproductive Immunology, vol. 65, pp. 99-103, 2011.

[73] L. Hee, I. Kirkegaard, P. Thorsen et al., "Low serum interleukin-17 is associated with preterm delivery," Acta
Obstetricia et Gynecologica Scandinavica, vol. 90, no. 1, pp. 92-96, 2011.

[74] C. Garlanda, C. A. Dinarello, and A. Mantovani, "The interleukin-1 family: back to the future," Immunity, vol. 39, pp. 1003-1018, 2013.

[75] G. Lopez-Castejon and D. Brough, "Understanding the mechanism of IL-1 $\beta$ secretion," Cytokine \& Growth Factor Reviews, vol. 22, pp. 189-195, 2011.

[76] C. E. Sutton, S. J. Lalor, C. M. Sweeney, C. F. Brereton, E. C. Lavelle, and K. H. G. Mills, "Interleukin-1 and IL-23 induce innate IL-17 production from $\gamma \delta \mathrm{T}$ cells, amplifying Th17 responses and autoimmunity," Immunity, vol. 31, pp. 331341, 2009.

[77] B. D. Taylor, G. Tang, R. B. Ness et al., "Mid-pregnancy circulating immune biomarkers in women with preeclampsia and normotensive controls," Pregnancy Hypertens, vol. 6, pp. 72-78, 2016.

[78] M. Traglia, L. A. Croen, K. L. Jones et al., "Cross-genetic determination of maternal and neonatal immune mediators during pregnancy," Genome Medicine, vol. 10, pp. 1-17, 2018.

[79] A. Molvarec, A. Szarka, S. Walentin et al., "Serum heat shock protein 70 levels in relation to circulating cytokines, chemokines, adhesion molecules and angiogenic factors in women with preeclampsia," Clinica Chimica Acta, vol. 412, pp. 1957-1962, 2011.

[80] S. Kudo, K. Mizuno, Y. Hirai, and T. Shimizu, "Clearance and tissue distribution of recombinant human interleukin 1 beta in rats," Cancer Research, vol. 50, pp. 5751-5755, 1990.

[81] S. H. Ross and D. A. Cantrell, "Signaling and function of interleukin-2 in T lymphocytes," Annual Review of Immunology, vol. 36, pp. 411-433, 2018.

[82] S. G. Holtan, Y. Chen, R. Kaimal et al., "Growth modeling of the maternal cytokine milieu throughout normal pregnancy: macrophage-derived chemokine decreases as inflammation/counterregulation increases," Journal of Immunology Research, vol. 2015, 11 pages, 2015.

[83] Y. Hamai, T. Fujii, T. Yamashita et al., "Evidence for an elevation in serum interleukin-2 and tumor necrosis factor- $\alpha$ levels before the clinical manifestations of preeclampsia," American Journal of Reproductive Immunology, vol. 38, pp. 89-93, 1997.

[84] M. D. Turner, B. Nedjai, T. Hurst, and D. J. Pennington, "Cytokines and chemokines: at the crossroads of cell signalling and inflammatory disease," Biochimica et Biophysica Acta, vol. 1843, pp. 2563-2582, 2014.

[85] A. Li, S. Dubey, M. L. Varney, B. J. Dave, and R. K. Singh, "IL8 directly enhanced endothelial cell survival, proliferation, and matrix metalloproteinases production and regulated angiogenesis," Journal of Immunology, vol. 170, pp. 33693376, 2003.

[86] M. Zygmunt, F. Herr, K. Münstedt, U. Lang, and O. D. Liang, "Angiogenesis and vasculogenesis in pregnancy," European Journal of Obstetrics, Gynecology, and Reproductive Biology, vol. 110, pp. S10-S18, 2003.

[87] W. T. Watford, M. Moriguchi, A. Morinobu, and J. J. O'Shea, "The biology of IL-12: coordinating innate and adaptive immune responses," Cytokine \& Growth Factor Reviews, vol. 14, pp. 361-368, 2003.

[88] X. Ma, W. Yan, H. Zheng et al., "Regulation of IL-10 and IL12 production and function in macrophages and dendritic cells," F1000Research, vol. 4, 2015. 
[89] R. H. P. Wilbers, D. R. Van Raaij, L. B. Westerhof, J. Bakker, G. Smant, and A. Schots, "Re-evaluation of IL-10 signaling reveals novel insights on the contribution of the intracellular domain of the IL-10R2 chain," PLoS One, vol. 12, 2017.

[90] A. D’andrea, M. Aste-Amezaga, N. M. Valiante, X. Ma, M. Kubin, and G. Trinchieri, "Interleukin 10 (IL-10) Inhibits human lymphocyte interferon $\gamma$-production by suppressing natural killer cell stimulatory factor/IL-12 synthesis in accessory cells," The Journal of Experimental Medicine, vol. 178, pp. 1041-1048, 1993.

[91] M. Mobini, M. Mortazavi, S. Nadi, M. Zare-Bidaki, S. Pourtalebi, and K. A. Mohammad, "Significant roles played by interleukin-10 in outcome of pregnancy," Iranian Journal of Basic Medical Sciences, vol. 19, pp. 119-124, 2016.

[92] C. Y. Yue, B. Zhang, and C. M. Ying, "Elevated serum level of IL-35 associated with the maintenance of maternal-fetal immune tolerance in normal pregnancy," PLoS One, vol. 10, article e0128219, 2015.

[93] P. Chatterjee, L. C. Valorie, R. B. Kelsey, and M. M. Brett, "Regulation of the anti-inflammatory cytokines interleukin4 and interleukin-10 during pregnancy," Frontiers in Immunology, vol. 5, 2014.

[94] A. Kumar, N. Begum, S. Prasad, S. Aggarwal, and S. Sharma, "Oral dydrogesterone treatment during early pregnancy to prevent recurrent pregnancy loss and its role in modulation of cytokine production: a double-blind, randomized, parallel, placebo-controlled trial," Fertility and Sterility, vol. 102, pp. 1357-1363, 2014.

[95] T. J. Kaitu'u-Lino, L. Tuohey, and S. Tong, "Maternal serum interleukin-33 and soluble ST2 across early pregnancy, and their association with miscarriage," Journal of Reproductive Immunology, vol. 95, pp. 46-49, 2012.

[96] M. D. Salazar Garcia, Y. Mobley, J. Henson et al., "Early pregnancy immune biomarkers in peripheral blood may predict preeclampsia," Journal of Reproductive Immunology, vol. 125, pp. 25-31, 2018.

[97] A. Kumar, N. Begum, S. Prasad, S. Agarwal, and S. Sharma, "IL-10, TNF- $\alpha$ \& IFN- $\gamma$ : potential early biomarkers for preeclampsia," Cellular Immunology, vol. 283, pp. 70-74, 2013.

[98] S. Cui, Y. Gao, L. Zhang et al., "Combined use of serum MCP1/IL-10 ratio and uterine artery Doppler index significantly improves the prediction of preeclampsia," Clinica Chimica Acta, vol. 473, pp. 228-236, 2017.

[99] A. Kumar, N. Begum, S. Prasad et al., "Role of cytokines in development of pre-eclampsia associated with periodontal disease - cohort study," Journal of Clinical Periodontology, vol. 41, pp. 357-365, 2014.

[100] J. Jeon, Y. Kim, E. Choi et al., "Implication of co-measured platelet factor 4 in the reliability of the results of the plasma transforming growth factor- $\beta 1$ measurement," Cytokine, vol. 16, pp. 102-105, 2001.

[101] D. Sharma, J. Bhattacharjee, A. Singh, and S. S. Trivedi, "Role of endothelin and inflammatory cytokines in pre-eclampsia a pilot North Indian study," American Journal of Reproductive Immunology, vol. 65, pp. 428-432, 2011.

[102] L. Rustveld, S. Kelsey, and R. Sharma, "Association between maternal infections and preeclampsia: a systematic review of epidemiologic studies," Maternal and Child Health Journal, vol. 12, pp. 223-242, 2008.

[103] C. Giurgescu, N. Sanguanklin, C. G. Engeland et al., "Relationships among psychosocial factors, biomarkers, pre- eclampsia, and preterm birth in African American women: a pilot," Applied Nursing Research, vol. 28, pp. e1-e6, 2015.

[104] Y. Ma, J. Zhang, C. C. Ruan, P. J. Gao, and Y. Ye, "Immune imbalance is associated with the development of preeclampsia," Medicine, vol. 98, article e15080, 2019.

[105] N. R. Maharaj, A. Phulukdaree, S. Nagiah, P. Ramkaran, C. Tiloke, and A. A. Chuturgoon, "Pro-inflammatory cytokine levels in HIV infected and uninfected pregnant women with and without preeclampsia," PLoS One, vol. 12, article e0170063, 2017.

[106] N. R. Maharaj, P. Ramkaran, S. Pillay, and A. A. Chuturgoon, "MicroRNA-146a rs2910164 is associated with severe preeclampsia in Black South African women on HAART," BMC Genetics, vol. 18, 2017.

[107] K. H. Bakheit, N. K. Bayoumi, A. M. Eltom, M. I. Elbashir, and I. Adam, "Cytokines profiles in sudanese women with preeclampsia," Hypertension in Pregnancy, vol. 28, pp. 224229, 2009.

[108] P. Zubor, K. Dokus, I. Zigo, J. Danko, M. Skerenova, and R. Pullmann, "TNF- $\alpha$ G308A gene polymorphism has an impact on renal function, microvascular permeability, organ involvement and severity of preeclampsia," Gynecologic and Obstetric Investigation, vol. 78, pp. 150-161, 2014.

[109] Y. Üstün, Y. Engin-Üstün, E. Özkaplan, B. Otlu, and T. M. Sait, "Association of helicobacter pylori infection with systemic inflammation in preeclampsia," The Journal of Maternal-Fetal \& Neonatal Medicine, vol. 23, pp. 311-314, 2010.

[110] A. Molvarec, A. Szarka, S. Walentin et al., "Serum leptin levels in relation to circulating cytokines, chemokines, adhesion molecules and angiogenic factors in normal pregnancy and preeclampsia," Reproductive Biology and Endocrinology, vol. 9, p. 124, 2011.

[111] D. Mihu, C. Razvan, A. Malutan, and C. Mihaela, "Evaluation of maternal systemic inflammatory response in preeclampsia," Taiwanese Journal of Obstetrics \& Gynecology, vol. 54, pp. 160-166, 2015.

[112] M. Cakmak, E. Baplar, H. Yilmaz et al., "Serum levels of endocan correlate with the presence and severity of pre-eclampsia," Clinical and Experimental Hypertension, vol. 38, pp. 137-142, 2016.

[113] K. Uckan and H. G. Sahin, "Serum amyloid A, procalcitonin, highly sensitive $\mathrm{C}$ reactive protein and tumor necrosis factor alpha levels and acute inflammatory response in patients with hemolysis, elevated liver enzymes, low platelet count (HELLP) and eclampsia," The Journal of Obstetrics and Gynaecology Research, vol. 44, pp. 440-447, 2018.

[114] A. Singh, D. Sharma, J. Bhattacharjee, and C. Raghunandan, "Role of inflammatory cytokines and eNOS gene polymorphism in pathophysiology of pre-eclampsia," American Journal of Reproductive Immunology, vol. 63, pp. 244-251, 2010.

[115] M. A. Guven, A. Coskun, I. E. Ertas, M. Aral, B. Zencirci, and H. Oksuz, "Association of maternal serum CRP, IL-6, TNF- $\alpha$, homocysteine, folic acid and vitamin b12 levels with the severity of preeclampsia and fetal birth weight," Hypertension in Pregnancy, vol. 28, pp. 190-200, 2009.

[116] A. Ozler, A. Turgut, M. E. Sak et al., "Serum levels of neopterin, tumor necrosis factor-alpha and Interleukin- 6 in preeclampsia: relationship with disease severity," European Review for Medical and Pharmacological Sciences, vol. 16, pp. 1707-1712, 2012. 
[117] G. J. Mundim, M. C. Paschoini, E. Araujo Júnior, C. F. Da Silva, and J. V. Rodrigues, "Assessment of angiogenesis modulators in pregnant women with pre-eclampsia: a case-control study," Archives of Gynecology and Obstetrics, vol. 293, pp. 369-375, 2016.

[118] M. W. Cunningham, T. Ibrahim, D. Cornelius, L. Amaral, V. R. Vaka, and B. LaMarca, "The role of interleukin-2 (IL2) in natural killer cell (NK) activation and hypertension in a preclinical rat model of preeclampsia," FASEB Journal, vol. 32, 2018.

[119] M. Tosun, H. Celik, E. Yavuz, T. Alper, E. Malatyalioğlu, and B. Avci, "Maternal and umbilical serum levels of interleukin6 , interleukin-8, and tumor necrosis factor- $\alpha$ in normal pregnancies and in pregnancies complicated by preeclampsia," The Journal of Maternal-Fetal \& Neonatal Medicine, vol. 23, pp. 880-886, 2010.

[120] C. Rădulescu, A. Bacârea, A. Huțanu, N. Şincu, and S. Bățagă, "Helicobacter pylori infection and pre-eclampsia in a Romanian study group," International Journal of Gynaecology and Obstetrics, vol. 135, pp. 328-329, 2016.

[121] Q. Chen, M. Zhao, F. Guo et al., "The reduction of circulating levels of IL-6 in pregnant women with preeclampsia by magnesium sulphate and nifedipine: in vitro evidence for potential mechanisms," Placenta, vol. 36, pp. 661-666, 2015.

[122] U. A. Nayeri, I. A. Buhimschi, C. A. Laky et al., "Antenatal corticosteroids impact the inflammatory rather than the antiangiogenic profile of women with preeclampsia," Hypertension, vol. 63, pp. 1285-1292, 2014.

[123] M. Kalinderis, A. Papanikolaou, B. C. Tarlatzis et al., "Elevated serum levels of interleukin-6, interleukin- $1 \beta$ and human chorionic gonadotropin in pre-eclampsia," American Journal of Reproductive Immunology, vol. 66, pp. 468-475, 2011.

[124] W. Ramma, G. Zhao, A. Ahmed et al., "The elevation in circulating anti-angiogenic factors is independent of markers of neutrophil activation in preeclampsia," Angiogenesis, vol. 15, pp. 333-340, 2012.

[125] J. P. Xiao, Y. X. Yin, Y. F. Gao et al., "The increased maternal serum levels of IL- 6 are associated with the severity and onset of preeclampsia," Cytokine, vol. 60, pp. 856-860, 2012.

[126] Z. Zhang, Y. Gao, L. Zhang et al., "Alterations of IL-6, IL-6R and gp130 in early and late onset severe preeclampsia," Hypertension in Pregnancy, vol. 32, pp. 270-280, 2013.

[127] A. E. Kara, G. Guney, A. Tokmak, and G. Ozaksit, "The role of inflammatory markers hs-CRP, sialic acid, and IL-6 in the pathogenesis of preeclampsia and intrauterine growth restriction," European Cytokine Network, vol. 30, pp. 29-33, 2019.

[128] M. Küçük, S. D. Sezer, H. Yüksel, A. R. Odabaşi, and C. Yenisey, "Comparison of interleukin-6 levels in maternal and umbilical cord blood in early- and late-onset preeclampsia," Gynecological Endocrinology, vol. 28, pp. 640643, 2012.

[129] C. I. Duvan, E. A. Keskin, Y. Onaran, S. Simavli, N. O. Turhan, and C. Koca, "Is the level of maternal serum prohepcidin associated with preeclampsia?," Hypertension in Pregnancy, vol. 34, pp. 145-152, 2015.

[130] D. Darmochwal-Kolarz, M. Michalak, B. Kolarz et al., "The role of interleukin-17, interleukin-23, and transforming growth factor- $\beta$ in pregnancy complicated by placental insufficiency," BioMed Research International, vol. 2017, 5 pages, 2017.
[131] H. Seol, E. Lee, S. Jung et al., "Serum levels of YKL-40 and interleukin-18 and their relationship to disease severity in patients with preeclampsia," Journal of Reproductive Immunology, vol. 79, pp. 183-187, 2009.

[132] T. T. Kanninen, A. Jayaram, S. Jaffe Lifshitz, and S. S. Witkin, "Altered autophagy induction by sera from pregnant women with pre-eclampsia: a case-control study," BJOG, vol. 121, pp. 958-964, 2014.

[133] S. Feizollahzadeh, R. Taheripanah, M. Khani, B. Farokhi, and D. Amani, "Promoter region polymorphisms in the transforming growth factor beta-1 (TGF beta 1) gene and serum TGF beta 1 concentration in preeclamptic and control Iranian women," Journal of Reproductive Immunology, vol. 94, pp. 216-221, 2012.

[134] F. Anvari, F. Dabagh-Gorjani, M. Soltani-Zangbar, E. Kamali-Sarvestani, Z. Malek-Hosseini, and B. GharesiFard, "Investigating the association of IL-17A and IL-17F with susceptibility to pre-eclampsia in Iranian women," Iranian Journal of Immunology, vol. 12, pp. 117-128, 2015.

[135] I. E. Gökdemir, O. Özdeğirmenci, B. Elmas et al., "Evaluation of ADAMTS12, ADAMTS16, ADAMTS18 and IL-33 serum levels in pre-eclampsia," The Journal of Maternal-Fetal \& Neonatal Medicine, vol. 29, pp. 2451-2456, 2016.

[136] I. Alanbay, H. Coksuer, C. M. Ercan et al., "Chitotriosidase, interleukin-1 beta and tumor necrosis factor alpha levels in mild preeclampsia," Archives of Gynecology and Obstetrics, vol. 285, pp. 1505-1511, 2012.

[137] T. M. Elhawary, H. D. Demerdash, and M. A. Sweilam, "Relationship between interleukin-10 polymorphism and maternal serum leptin level in preeclampsia," Clinical and Experimental Hypertension, vol. 35, pp. 367-372, 2013.

[138] R. Aggarwal, M. Kohli, P. Jawanjal, G. Rath, A. K. Jain, and P. Mittal, "Association of pro- and anti-inflammatory cytokines in preeclampsia," Journal of Clinical Laboratory Analysis, vol. 33, 2019.

[139] G. B. Dealtry, M. O'Farrell, and N. Fernandez, "The Th2 cytokine environment of the placenta," International Archives of Allergy and Immunology, vol. 123, pp. 107-119, 2000.

[140] J. M. Roberts and C. Escudero, "The placenta in preeclampsia," Pregnancy Hypertension: An International Journal of Women's Cardiovascular Health, vol. 2, pp. 72-83, 2012.

[141] M. S. Longtine and D. M. Nelson, "Placental dysfunction and fetal programming. The importance of placental size, shape, histopathology, and molecular composition," Seminars in Reproductive Medicine, vol. 29, pp. 187-196, 2011.

[142] H. M. Georgiou, Y. S. Thio, C. Russell et al., "Association between maternal serum cytokine profiles at 7-10 weeks' gestation and birthweight in small for gestational age infants," Obstetrics and Gynecology, vol. 204, pp. 415-415, 2011.

[143] B. D. Taylor, R. B. Ness, M. A. Klebanoff et al., "The impact of female fetal sex on preeclampsia and the maternal immune milieu," Pregnancy Hypertens, vol. 12, pp. 53-57, 2018.

[144] T. Cift, S. Uludag, Y. Aydin, and A. Benian, "Effects of amniotic and maternal CD-146, TGF- $\beta 1$, IL- 12 , IL-18 and IFN- $\gamma$, on adverse pregnancy outcome," The Journal of MaternalFetal \& Neonatal Medicine, vol. 26, pp. 21-25, 2013.

[145] L. Karlsson, N. Nousiainen, N. M. Scheinin et al., "Cytokine profile and maternal depression and anxiety symptoms in mid-pregnancy-the FinnBrain Birth Cohort Study," Archives of Women's Mental Health, vol. 20, pp. 39-48, 2017. 
[146] S. R. Lindehammer, M. Fex, I. Hanson, A. Lernmark, M. Maziarz, and K. Maršál, "Early-pregnancy cytokines in mothers to children developing multiple, persistent islet autoantibodies, type 1 diabetes, or both before 7 years of age," American Journal of Reproductive Immunology, vol. 66, pp. 495-503, 2011.

[147] K. Cheslack-Postava, S. Cremers, Y. Bao, L. Shen, C. A. Schaefer, and A. S. Brown, "Maternal serum cytokine levels and risk of bipolar disorder," Brain, Behavior, and Immunity, vol. 63, pp. 108-114, 2017.

[148] A. Herrera-Muñoz, A. M. Fernández-Alonso, N. FischerSuárez, P. Chedraui, and F. R. Pérez-López, "Maternal serum cytokine levels in pregnancies complicated with threatened preterm labour," Gynecological Endocrinology, vol. 33, pp. 408-412, 2017.

[149] E. M. McSorley, A. J. Yeates, M. S. Mulhern et al., “Associations of maternal immune response with $\mathrm{MeHg}$ exposure at 28 weeks' gestation in the Seychelles Child Development Study," American Journal of Reproductive Immunology, vol. 80, 2018.

[150] J. L. Irwin, G. E. Watson, K. Grzesik et al., "Maternal immune markers during pregnancy and child neurodevelopmental outcomes at age 20 months in the Seychelles Child Development Study," Journal of Neuroimmunology, vol. 335, 2019.

[151] L. Ma, Q. Lu, J. Ouyang et al., "How are maternal dietary patterns and maternal/fetal cytokines associated with birth weight? A path analysis," The British Journal of Nutrition, vol. 121, pp. 1178-1187, 2019.

[152] M. A. Buxton, N. Meraz-Cruz, B. N. Sanchez et al., "Air pollution and inflammation: findings from concurrent repeated measures of systemic and reproductive tract cytokines during term pregnancy in Mexico City," Science of The Total Environment, vol. 681, pp. 235-241, 2019.

[153] A. Syngelaki, G. H. A. Visser, K. Krithinakis, A. Wright, and K. H. Nicolaides, "First trimester screening for gestational diabetes mellitus by maternal factors and markers of inflammation," Metabolism, Clinical and Experimental, vol. 65, pp. 131-137, 2016.

[154] T. Fiorini, P. Vianna, P. Weidlich et al., "Relationship between cytokine levels in serum and gingival crevicular fluid (GCF) in pregnant women," Cytokine, vol. 58, pp. 34-39, 2012.

[155] M. Coussons-Read, M. Lobel, J. C. Carey et al., "The occurrence of preterm delivery is linked to pregnancy-specific distress and elevated inflammatory markers across gestation," Brain, Behavior, and Immunity, vol. 26, pp. 650-659, 2012.

[156] E. R. Blackmore, J. A. Moynihan, T. G. O'Connor, M. Mittal, X. Cai, and M. M. Matthieu, "Lifetime exposure to intimate partner violence and proinflammatory cytokine levels across the perinatal period," Journal of Women's Health, vol. 25, pp. 1004-1013, 2016.

[157] X. Qu, B. Jia, X. Yu et al., "Association of downregulated HDAC 2 with the impaired mitochondrial function and cytokine secretion in the monocytes/macrophages from gestational diabetes mellitus patients," Cell Biology International, vol. 40, pp. 642-651, 2016.

[158] L. M. Blair, K. Porter, B. Leblebicioglu, and L. M. Christian, "Poor sleep quality and associated inflammation predict preterm birth: heightened risk among African Americans," Sleep, vol. 38, pp. 1259-1267, 2015.

[159] S. Kim, V. Sy, T. Araki et al., "Total adiponectin, but not inflammatory markers C-reactive protein, tumor necrosis factor-alpha, interluekin- 6 and monocyte chemoattractant protein-1, correlates with increasing glucose intolerance in pregnant Chinese-Americans," Journal of Diabetes, vol. 6, pp. 360-368, 2014.

[160] Ö. Özçaka, B. Ceyhan-Öztürk, P. Gümüş, A. Akcalı, A. Nalbantsoy, and N. Buduneli, "Clinical periodontal status and inflammatory cytokines in gestational diabetes mellitus," Archives of Oral Biology, vol. 72, pp. 87-91, 2016.

[161] K. R. Bobbitt, R. M. Peters, J. Li, S. D. Rao, K. J. Woodcroft, and A. Cassidy-Bushrow, "Early pregnancy vitamin D and patterns of antenatal inflammation in African-American women," Journal of Reproductive Immunology, vol. 107, pp. 52-58, 2015.

[162] A. S. Bossick, R. M. Peters, C. Burmeister, N. Kakumanu, J. E. Shill, and A. Cassidy-Bushrow, "Antenatal inflammation and gestational diabetes mellitus risk among pregnant AfricanAmerican women," Journal of Reproductive Immunology, vol. 115, pp. 1-5, 2016.

[163] J. Catov, M. Flint, M. Lee, J. Roberts, and D. Abatemarco, "The relationship between race, inflammation and psychosocial factors among pregnant women," Maternal and Child Health Journal, vol. 19, pp. 401-409, 2015.

[164] J. Zhang, Y. Xu, H. Chi et al., "Interleukin 6 (IL-6) and tumor necrosis factor $\alpha$ (TNF- $\alpha$ ) single nucleotide polymorphisms (SNPs), inflammation and metabolism in gestational diabetes mellitus in Inner Mongolia," Medical Science Monitor, vol. 23, pp. 4149-4157, 2017.

[165] O. O. Ayoola, A. Whatmore, J. K. Cruickshank, P. E. Clayton, W. O. Balogun, and O. O. Jarrett, "Maternal malaria status and metabolic profiles in pregnancy and in cord blood: relationships with birth size in Nigerian infants," Malaria Journal, vol. 11, 2012.

[166] F. O. Braga, M. F. B. da Matta, M. B. Gomes, C. A. Negrato, and J. R. I. Carneiro, "Relationship between inflammatory markers, glycated hemoglobin and placental weight on fetal outcomes in women with gestational diabetes," Archives of endocrinology and metabolism, vol. 63, pp. 22-29, 2019.

[167] A. Mohammed and I. S. Aliyu, "Maternal serum level of TNF- $\alpha$ in Nigerian women with gestational diabetes mellitus," The Pan African Medical Journal, vol. 31, 2018.

[168] A. Mohammed, I. S. Aliyu, and M. Manu, "Correlation between circulating level of tumor necrosis factor-alpha and insulin resistance in Nigerian women with gestational diabetes mellitus," Annals of African Medicine, vol. 17, pp. 168171, 2018.

[169] I. Danielsen, C. Granström, D. Rytter et al., "Subclinical inflammation during third trimester of pregnancy was not associated with markers of the metabolic syndrome in young adult offspring," Obesity (Silver Spring), vol. 22, no. 5, pp. 1351-1358, 2014.

[170] E. Gilman Stephen, H. Mady, G. Akhgar et al., "Socioeconomic disadvantage, gestational immune activity, and neurodevelopment in early childhood," Proceedings of the National Academy of Sciences, vol. 114, p. 6728, 2017.

[171] S. E. Gilman, J. Hahn, S. Cherkerzian, J. M. Goldstein, S. L. Buka, and M. Hornig, "Prenatal immune programming of the sex-dependent risk for major depression," Translational Psychiatry, vol. 6, article e822, 2016.

[172] L. Hrolfsdottir, B. E. Birgisdottir, I. Gunnarsdottir et al., "Maternal diet, gestational weight gain, and inflammatory markers during pregnancy," Obesity, vol. 24, pp. 2133-2139, 2016. 
[173] Z. Niu, F. Tian, P. Ding et al., "Mediating role of maternal serum interleukin-1beta and tumor necrosis factor-alpha in the association between environmental tobacco smoke exposure in pregnancy and low birth weight at term," The Journal of Maternal-Fetal \& Neonatal Medicine, vol. 31, pp. 12511258, 2018.

[174] J. L. Bartha, A. Fernández-Deudero, F. Bugatto, M. FajardoExposito, N. González-González, and B. Hervías-Vivancos, "Inflammation and cardiovascular risk in women with preterm labor," Journal of Women's Health, vol. 21, pp. 643648, 2012.

[175] R. Saucedo, A. Zarate, L. Basurto et al., "Relationship between circulating adipokines and insulin resistance during pregnancy and postpartum in women with gestational diabetes," Archives of Medical Research, vol. 42, pp. 318-323, 2011.

[176] R. Buglione-Corbett, K. Deligiannidis, K. Leung et al., "Expression of inflammatory markers in women with perinatal depressive symptoms," Archives of Women's Mental Health, vol. 21, pp. 671-679, 2018.

[177] J. M. Goldstein, S. Cherkerzian, A. G. Remington et al., "Prenatal maternal immune disruption and sex-dependent risk for psychoses," Psychological Medicine, vol. 44, pp. 32493261, 2014.

[178] M. Drozdzik, N. Szlarb, and M. Kurzawski, "Interleukin-6 level and gene polymorphism in spontaneous miscarriage," Tissue Antigens, vol. 82, pp. 171-176, 2013.

[179] D. Hassiakos, I. Lambrinoudaki, L. Aravantinos et al., "Increased maternal serum interleukin-6 concentrations at 11 to 14 weeks of gestation in low risk pregnancies complicated with gestational diabetes mellitus: development of a prediction model," Hormone and Metabolic Research, vol. 48, pp. 35-41, 2015.

[180] S. K. Abell, S. Shorakae, C. L. Harrison et al., "The association between dysregulated adipocytokines in early pregnancy and development of gestational diabetes," Diabetes/Metabolism Research and Reviews, vol. 33, 2017.

[181] E. E. Accortt, C. D. Schetter, R. M. Peters, and A. CassidyBushrow, "Lower prenatal vitamin D status and postpartum depressive symptomatology in African American women: preliminary evidence for moderation by inflammatory cytokines," Archives of Women's Mental Health, vol. 19, pp. 373-383, 2016.

[182] S. L. Gillespie and L. M. Christian, "Body mass index as a measure of obesity: racial differences in predictive value for health parameters during pregnancy," Journal of Women's Health, vol. 25, pp. 1210-1218, 2016.

[183] M. Kuzmicki, B. Telejko, A. Zonenberg et al., "High resistin and interleukin-6 levels are associated with gestational diabetes mellitus," Gynecological Endocrinology, vol. 25, pp. 258263, 2009.

[184] S. Nazzari, P. Fearon, F. Rice et al., "Beyond the HPA-axis: exploring maternal prenatal influences on birth outcomes and stress reactivity," Psychoneuroendocrinology, vol. 101, pp. 253-262, 2019.

[185] S. Eghbal-Fard, M. Nouri, M. Yousefi et al., "The imbalance of Th17/Treg axis involved in the pathogenesis of preeclampsia," Journal of Cellular Physiology, vol. 234, pp. 5106-5116, 2019.

[186] A. Molvarec, I. Czegle, J. Szijártó, and J. J. Rigó, "Increased circulating interleukin-17 levels in preeclampsia," Journal of Reproductive Immunology, vol. 112, pp. 53-57, 2015.
[187] T. B. Pereira, E. B. Thomaz, F. R. Nascimento et al., "Regulatory cytokine expression and preterm birth: case-control study nested in a cohort," PLoS One, vol. 11, article e0158380, 2016.

[188] K. Rytlewski, H. Huras, K. Kuśmierska-Urban, A. Gałaś, and A. Reroń, "Leptin and interferon-gamma as possible predictors of cesarean section among women with hypertensive disorders of pregnancy," Medical Science Monitor, vol. 18, pp. CR506-CR511, 2012.

[189] M. A. Ahmed, A. I. Alqosaibi, M. A. Mohamed, and M. G. Soliman, "Evaluation of some cytokines and gene expressions in pre-eclampsia," Pakistan Journal of Biological Sciences, vol. 22, pp. 148-153, 2019.

[190] A. A. El Shahaway, R. R. Abd Elhady, A. A. Abdelrhman, and S. Yahia, "Role of maternal serum interleukin 17 in preeclampsia: diagnosis and prognosis," Journal of Inflammation Research, vol. 12, pp. 175-180, 2019. 